\title{
Heterogeneous catalysis with encapsulated haem and other synthetic porphyrins: Harnessing the power of porphyrins for oxidation reactions
}

https://doi.org/10.1515/chem-2018-0083

received March 3, 2018; accepted April 24, 2018.

\begin{abstract}
Encapsulated metalloporphyrins have been widely studied for their use as efficient heterogeneous catalysts, inspired by the known catalytic activity of porphyrins in haemoproteins. The oxidation of organic substrates by haemoproteins is one of the well-known roles of these proteins, in which the haem (ferriprotoporphyrin IX = FePPIX) cofactor is the centre of reactivity. While these porphyrins are highly efficient catalysts in the protein environment, once removed, they quickly lose their reactivity. It is for this reason that they have garnered much interest in the field of heterogeneous catalysis of oxidation reactions. This review details current research in the field, focusing on the application of encapsulated haem, and other synthetic metalloporphyrins, applied to oxidation reactions.
\end{abstract}

Keywords: haem; heterogeneous catalysis; metalloporphyrins; MOFs; encapsulation; oxidation reactions.

\section{Introduction}

Oxidation of organic substrates, especially alcohols, is an important class of industrially relevant reactions [1] and therefore there has been much interest in developing heterogeneous catalysts for this purpose [1-3]. Heterogeneous catalysts provide many advantages in a synthetic environment such as ease of separation, waste minimisation and reusability [4,5]. It is for this reason that the development of such catalysts is a focus of green

\footnotetext{
*Corresponding author: Timothy J. Egan, Department of Chemistry, University of Cape Town, Private Bag, Rondebosch 7701, South Africa, E-mail: timothy.egan@uct.ac.za

Nicola A. Dare: Department of Chemistry, University of Cape Town, Private Bag, Rondebosch 7701, South Africa
}

chemistry since they eliminate the need for distillation or extraction to separate products from the catalyst $[5,6]$.

The oxidation of organic substrates in nature is one of the well-known roles of the class of metalloproteins known as haemoproteins [7]. These proteins contain iron protoporphyrin IX (haem or FePPIX) as a cofactor (Figure 1a) [8]. They are crucial in organisms where they are responsible for a wide variety of metabolic functions such as gas binding (e.g. haemo- and myoglobin) [9], electron transport (e.g. cytochromes $a, b$ and $c$ ) [10], ligand sensing (e.g. guanylyl cyclase) [11] and redox catalysis (e.g. cytochrome P450s and peroxidases such as horseradish peroxidase, HRP Figure 1b) $[7,8,12]$. By making use of the FePPIX cofactor, haemoproteins have been shown to catalyse reactions with high stereo-, chemo- and regioselectivity $[13,14]$.

The centre of reactivity of catalytic haemoproteins is the haem co-factor, where the resting state of haem typically consists of a six-coordinate low-spin Fe(III) centre with axial coordination to a protein residue and an axial water ligand [16]. While haemoproteins can catalyse both oxidative and reductive chemistry, the catalysis of oxidative reactions has been the focus of much of the research in this area. In this context, there are two broad classes of oxidative haem enzymes, namely; (i) oxygenases (e.g. cytochromes $\mathrm{P} 450$ ) which use $\mathrm{O}_{2}$ to oxidise, and usually oxygenate, substrates and (ii) peroxidases (e.g. HRP and cytochrome $c$ peroxidase) which use $\mathrm{H}_{2} \mathrm{O}_{2}$ as an oxidant [7]. While these two classes of oxidative enzymes both contain the haem cofactor, and therefore share a reactive intermediate, they differ in the type of reaction that they catalyse. Namely, peroxidases such as HRP do not catalyse the insertion of oxygen into $\mathrm{C}-\mathrm{H}$ bonds, but rather catalyse a two-electron oxidation of organic substrates Oxygenases such as P450s do not catalyse electron transfer reactions but rather catalyse several different classes of reactions, often including the insertion of oxygen, such hydroxylation and epoxidation of organic molecules, as well as breaking C-C bonds in substrates such as cholesterol $[7,17,18]$. This difference in reactivity 

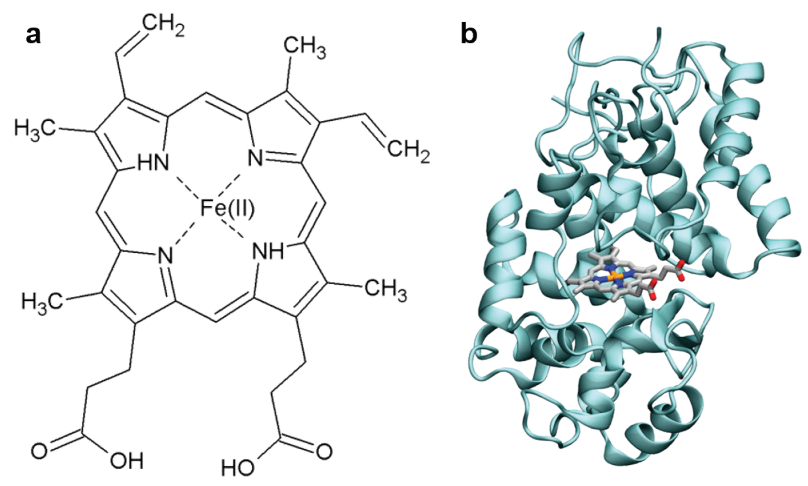

Figure 1: (a) Structure of haem or iron protoporphyrin IX (FePPIX) and (b) HRP with the haem cofactor highlighted. Possible axial ligands not shown for clarity. Protein structure generated using crystal structure data from the PDB [15].

is reflected in the environment around the haem centre, where cytochromes $P 450$ have a substrate binding pocket directly above the reaction centre, while in peroxidases the reaction centre is more sterically hindered [7]. Another significant difference between these classes of proteins is the identity of the proximal amino acids ligating the haem cofactor. These are histidine and cysteine in the case of HRPs and P450s, respectively [17].

When using native haemoproteins as catalysts, enzyme stability and interfering substances can be problematic when the native enzymes themselves are used. For example, in the case of horseradish peroxidase and glucose oxidases, commonly used enzymes, ascorbic acid, bilirubin, and iodine have been shown to interfere with the reaction and this can result in poor catalytic activity $[19,20]$. A common problem in both families of proteins, namely peroxidases and oxygenases, is protein inactivation occurring due to the production of free radicals which can react with, and destroy the haem cofactor $[19,20,18,21]$. Furthermore, in the case of cytochromes $P 450$, the formation of active substrate intermediates, which are capable of modifying haem and the apoenzyme, represents a further mode of protein inactivation.

While the oxidants used by both peroxidases and oxygenases $\left(\mathrm{H}_{2} \mathrm{O}_{2}\right.$ and $\mathrm{O}_{2}$, respectively) are potent, they are not inherently reactive molecules and thus require activation before oxidation can proceed. This reactivity is particularly unusual in the case of $\mathrm{O}_{2}$ since it has a large kinetic barrier to reactivity because of the spinforbidden reaction between spin-paired biomolecules and its paramagnetic electron arrangement (triplet state, $S=1$ compared to the typical singlet state, $S=0$ ) $[7,22]$. The barrier to reactivity is lowered by binding to the iron centre of the haem co-factor, where a one electron reduction occurs leading to the formation of an active oxidant [22]. For the reaction to occur, low spin [Fe(III) porphyrin] first undergoes a one electron reduction to form a reduced $\mathrm{Fe}(\mathrm{II})$ centre, to which $\mathrm{O}_{2}$ can bind. This forms a complex best described as ferric-superoxide, [Fe(III)$\mathrm{O}_{2}$-(porphyrin)] (Scheme 1). Subsequent protonation to [Fe(III)-OOH(porphyrin)] then occurs and, at this point, the mechanisms of oxygenases follows that of peroxidases [7]. In the case of peroxidases, the reaction is typically a twoelectron oxidation-reduction reaction [23]. The oxidant, $\mathrm{H}_{2} \mathrm{O}_{2}$, binds reversibly to the $\mathrm{Fe}(\mathrm{III})$ centre of the porphyrin (Fe(III)-OOH(porphyrin)]) with the loss of a proton. This species subsequently undergoes irreversible $\mathrm{O}-\mathrm{O}$ bond cleavage to form a high valent species, either with a twoelectron transfer to form $\left[\mathrm{Fe}(\mathrm{IV})=\mathrm{O}\right.$ (porphyrin) ${ }^{\bullet+}$ and $\mathrm{H}_{2} \mathrm{O}$ (heterolytic cleavage), or a one electron transfer $[\mathrm{Fe}(\mathrm{IV})=\mathrm{O}$ (porphyrin)] and $\bullet \mathrm{OH}$ species (homolytic cleavage) $[24,25]$. The type of cleavage will depend on the specific enzyme, as well as the substrate. For example, peroxidases undergo heterolytic cleavage upon binding of the oxidant $\mathrm{H}_{2} \mathrm{O}_{2}$, whereas cytochromes $\mathrm{P} 450$ have been shown to undergo homo- or heterolytic cleavage depending on the structure of the oxidant [26].

Heterolytic cleavage of the $\mathrm{O}-\mathrm{O}$ bond to form $\left[\mathrm{Fe}(\mathrm{IV})=\mathrm{O}\right.$ (porphyrin) ${ }^{\bullet+}$ is thought be promoted by simultaneous electron transfer from the porphyrin ring to the $\mathrm{Fe}-\mathrm{O}$ bond as the porphyrin $\pi$-cation radical is generated, coupled with the delivery of a $\mathrm{H}^{+}$ion to the distal oxygen, promoting the release of $\mathrm{H}_{2} \mathrm{O}$ and generation of an oxygen atom with 6 valence electrons, thereby forming $\left[\mathrm{Fe}(\mathrm{IV})=\mathrm{O}\right.$ (porphyrin) ${ }^{\bullet+}$, a species which is two oxidation states above the resting state, [Fe(III)porphyrin] [16,27]. Activation of the $\mathrm{O}-\mathrm{O}$ bond is enhanced by the introduction of electron rich axial ligands, such as tyrosine [27]. This $\left[\mathrm{Fe}(\mathrm{IV})=\mathrm{O}\right.$ (porphyrin) ${ }^{\bullet+}$ species has been proposed to be the key reactive intermediate in oxidation reactions, and will rapidly react to oxidise electron rich substrates in two subsequent one electron oxidation steps (Scheme 1) or oxygenate a substrate (as seen in oxidases) [22]. The precise structure of this high valent species and its subsequent interaction with the substrate is highly dependent on the protein structure, as well as substrate, and many detailed catalytic cycles have been proposed to describe this process [16]. Upon formation of the ferryl ion, this reactive intermediate will react with a variety of substrates depending on the nature of the haemoprotein. In the cases of oxygenases such as cytochrome $P 450$, regio- and stereoselective hydroxylation of aliphatic and aromatic hydrocarbons such as long chain fatty acids, norbornane, and cholesterol are very common reactions [28]. Scheme 2 shows the proposed mechanism for hydroxylation of an organic substrate by a radical generated from the ferryl ion [29]. 


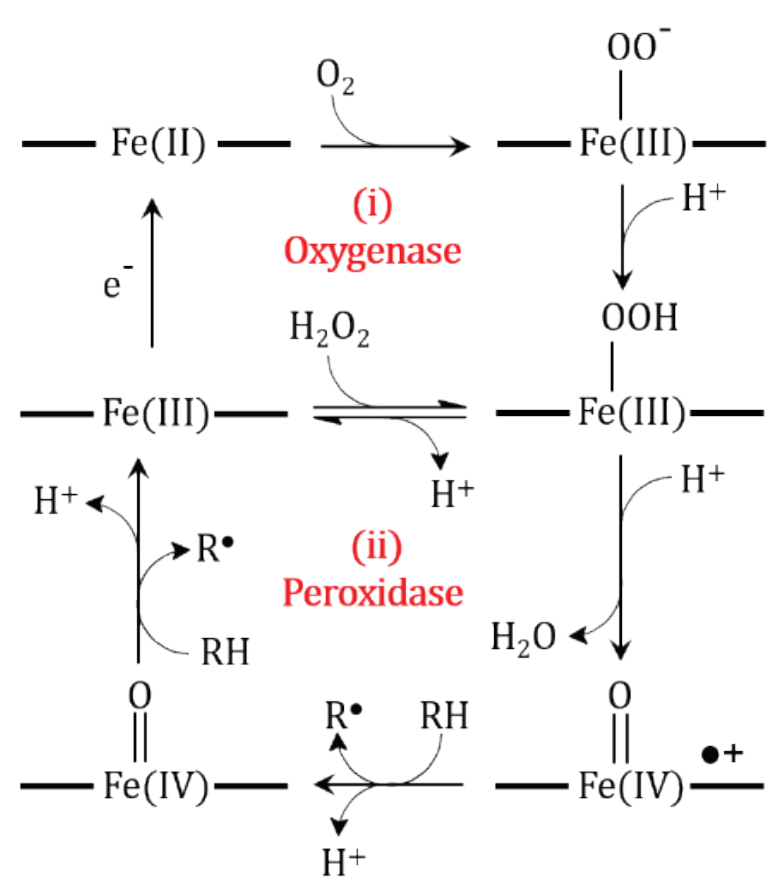

Scheme 1: Typical catalytic cycle of (i) oxygenase and (ii) peroxidase haemoproteins showing the formation of the high valent $\left.[\mathrm{Fe}(\mathrm{IV})=\mathrm{O} \text { (porphyrin })^{\bullet+}\right]$ intermediate and subsequent one electron oxidation steps of an electron rich substrate $\mathrm{RH}$ to reform [Fe(III) porphyrin]. In the diagram the thick black lines represent the plane of the porphyrin.

The importance of these proteins in biology has prompted extensive experimental and theoretical investigations into using either haem or synthetic derivatives of this molecule (e.g. tetraphenylporphines) as a catalyst. In studies on tetraphenylporphines, the oxidant iodosylbenzene (PhIO) is commonly used. In this case, PhIO will react with the $\mathrm{Fe}(\mathrm{III})$ centre to form the reactive $\left[\mathrm{Fe}(\mathrm{IV})=\mathrm{O}\right.$ (porphyrin) ${ }^{\bullet+}$ species, after activation of the $\mathrm{I}=\mathrm{O}$ bond [30]. There have been numerous studies investigating the ability of $\mathrm{Fe}(\mathrm{III})$ porphyrins dissolved in an aqueous solution to mimic the activity of enzymes such as cytochrome P-450 and horseradish peroxidase to catalyse the oxidation of organic substrates [24,25,31-38].

As mentioned above, one of the major drawbacks of metalloporphyrin catalysts in solution is that they can be degraded by hydroxyl radicals produced during peroxidation reactions and thus suffer from low recyclability $[24,39]$. Furthermore, while haem is very active in the protein pocket of an enzyme, once removed, the catalytic power decreases significantly. This is a result of a variety of factors including poor aqueous solubility, aggregation and irreversible oxidation in aqueous solutions [25,32].

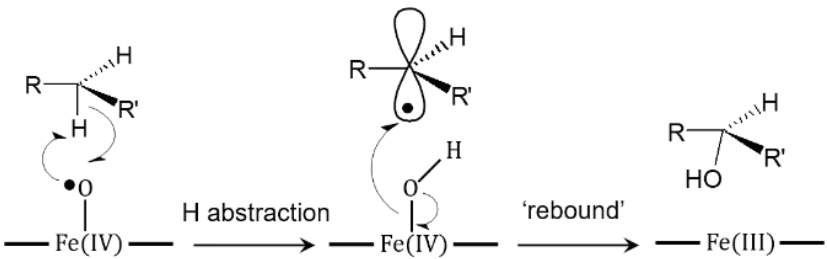

Scheme 2: Proposed reaction mechanism for hydroxylation of a substrate from the ferryl ion radical [29]. In the diagram the thick black lines represent the plane of the porphyrin.

It is for this reason that the immobilisation of FePPIX and synthetic porphyrin derivatives onto solid supports, forming heterogeneous catalysts has garnered much interest in recent years. By immobilising haem onto a solid support, problems which are prevalent in porphyrin homogeneous catalysts can be circumvented. Lately there has been a surge of interest in immobilising haem and synthetic porphyrins onto materials using different strategies with the aim of synthesising effective heterogeneous oxidation catalysts. This strategy has been used with great success where haem enzymes such as horseradish peroxidase and cytochrome $c$ have been immobilised onto materials such as gels [40-42], mesoporous sieves [43,44], and metal-organic frameworks $[45,46]$. These materials have shown increased stability due to the protection of the haem enzyme from catalytic degradation. This review will focus on the immobilisation of FePPIX and other synthetic porphyrins and not on immobilisation of the enzymes themselves. Interested readers are directed to a number of reviews focusing on that topic [47-51]. Another approach is the immobilisation of Fe(III)PPIX and synthetic porphyrins (rather than encapsulation) on surfaces such graphene, graphene oxide, polymers and $\mathrm{TiO}_{2}$ for a variety of applications. There are also a number of excellent reviews on this topic, and they have been purposefully left out of this review to avoid overlap [52-57]. This review will focus on the different strategies used to encapsulate Fe(III)PPIX (and will touch on other synthetic porphyrins) in solid supports, with a focus on metal-organic frameworks, for application as oxidation catalysis.

\section{Encapsulation of porphyrins in layered double hydroxides and mineral clays}

One of the first examples of immobilisation of porphyrins on mineral clays for application as heterogeneous catalysts 


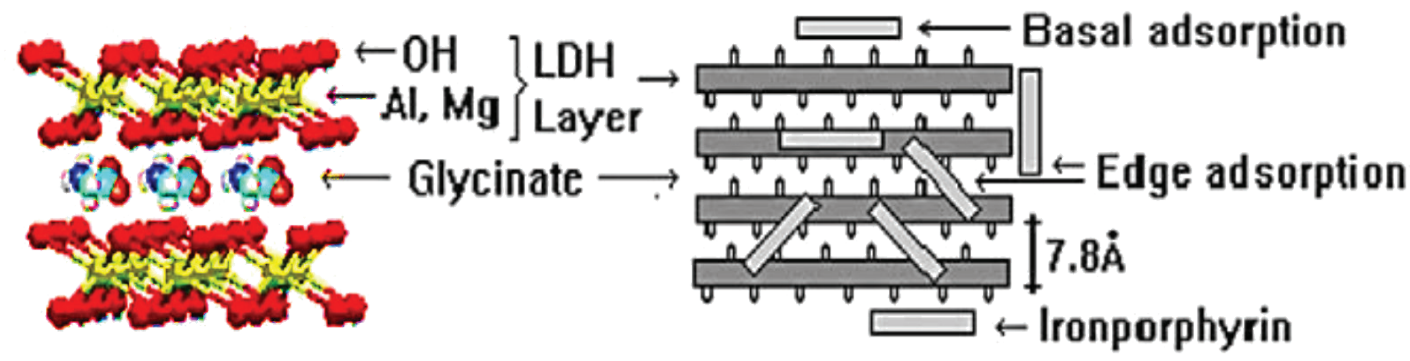

Figure 2: Schematic representation of Fe(III) porphyrins immobilised on LDH clay, intercalated with glycine [59]. Reprinted with permission from Ref. [59]. Copyright @ 2005, Elsevier.

was reported by Battioni and co-workers in 1990 [58]. In this study Mn(III) 5,10,15,20-tetrakis(1-methyl-4-pyridinio) porphyrin (TMPyP) was immobilised on montmorillonite, a silica based smectite clay. The immobilisation was conducted by stirring the porphyrin with the clay for 24 h. Successful immobilisation was confirmed by UV-visible spectroscopy and elemental analysis. The oxidation of alkanes (cyclooctane, cyclohexane, adamantane, heptane and pentane) with $\mathrm{PhIO}$ as the oxygen atom source was investigated. The supported porphyrin was found to have drastically improved activity relative to the analogous porphyrin in solution and was shown to be particularly active for short linear alkanes.

Nakagaki and co-workers immobilised two Fe(III) anionic porphyrins, [5,10,15,20-tetrakis(2-fluoro-6chlorophenyl-3-sulfonatophenyl)porphyrinate]; $\quad \mathrm{Fe}(\mathrm{III})$ TCFSPP) ${ }^{3-}$ ) and [5,10,15,20-tetrakis(2,6-difluorphenyl-3sulfonatophenyl)porphyrinate]; (Fe(III)TDFSPP) $)^{3-}$ ), onto exfoliated layered double hydroxides (LDH) [59]. The iron porphyrins were immobilised by reaction with preformed $\mathrm{Al}-\mathrm{Mg}$ layered hydroxides exfoliated with glycine under Ar and filtering off the resultant product (Figure 2). PXRD confirmed that the distance between the layers (7.8 A) did not change after loading of the Fe(III) porphyrins, therefore indicating that the metalloporphyrin is localised on the external basal planes and edges of the material.

The epoxidation of cyclooctene and oxidation of cyclohexane with the aid of PhIO by both synthesised catalysts was investigated. A mechanism for this reaction catalysed by an $\mathrm{Fe}(\mathrm{III})$ porphyrin has been proposed by Faria et al. and is shown in Scheme 3 [60]. It was found that both materials had a higher yield (87\%) of epoxidation with $\mathrm{Fe}(\mathrm{TCFSPP})$ than the porphyrin in solution. The oxidation of cyclohexane by Fe(TDFSPP)@GlyLDH showed a high alcohol vs. ketone selectivity, although the yield was low. It was interesting to note that the yield of the oxidation of cyclohexane increased from approximately $20-45 \%$ in the first cycle to $80-85 \%$ in the second and third cycles, respectively.

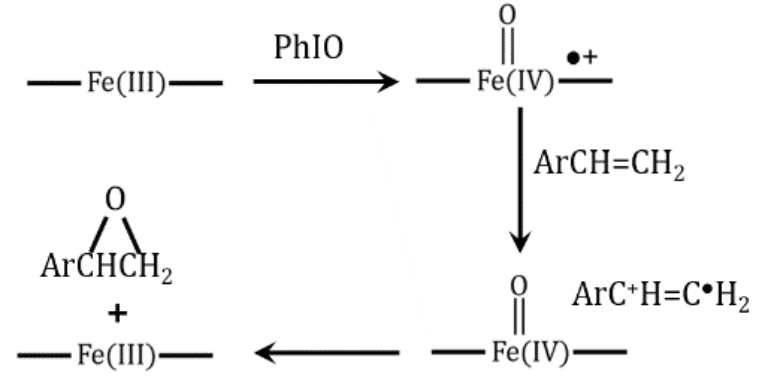

Scheme 3: Mechanism for epoxidation of an aromatic alkene by PhlO catalysed by an Fe(III) porphyrin.

While there are many examples of synthetic porphyrins being immobilised on a range of mineral clays and layered materials [61-63], there are only two examples of FePPIX itself being immobilised on these materials $[64,65]$. Inada and co-workers immobilised haemin (Fe(III) PPIX-Cl) on hectorite, a synthetic smectite mineral, but the material was not used for heterogeneous catalysis because it was found to be soluble after immobilisation of haemin and hence the "haem encapsulated catalyst" was homogeneous in nature.

Zhang et al. aimed to mimic the activity of HRP by synthesising a haemin-montmorillonite conjugate [65]. The surface of the montmorillonite clay was first functionalised with histidine residues to facilitate coordination of haemin to the clay. This procedure aimed to increase the loading of haemin on to the montmorillonite which was determined using UV-visible spectroscopy. The peroxidatic capability of the synthesised material was investigated using the oxidation of guaiacol, a commonly used reaction to assay the activity of HRP enzymes (Figure 3a). It was found that the histidine functionalised material had far greater activity than both the non-functionalised haemin@clay material as well as native haemin (Figure 3b). 
a

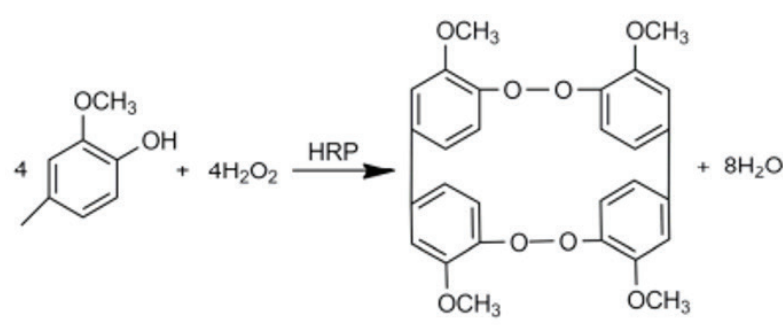

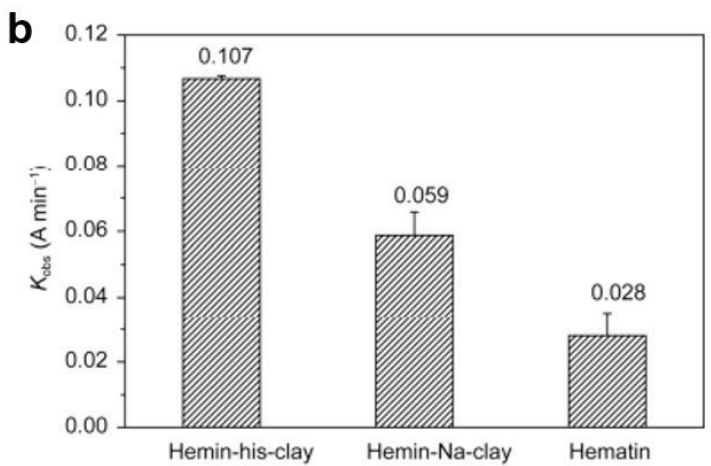

Figure 3: (a) Oxidation of guaiacol by $\mathrm{H}_{2} \mathrm{O}_{2}$ catalysed by HRP; (b) Observed rate constants of haemin@histidine-clay, haemin@clay and native haemin [65]. Reprinted with permission from Ref. [65]. Copyright ( 2015 , SpringerLink.

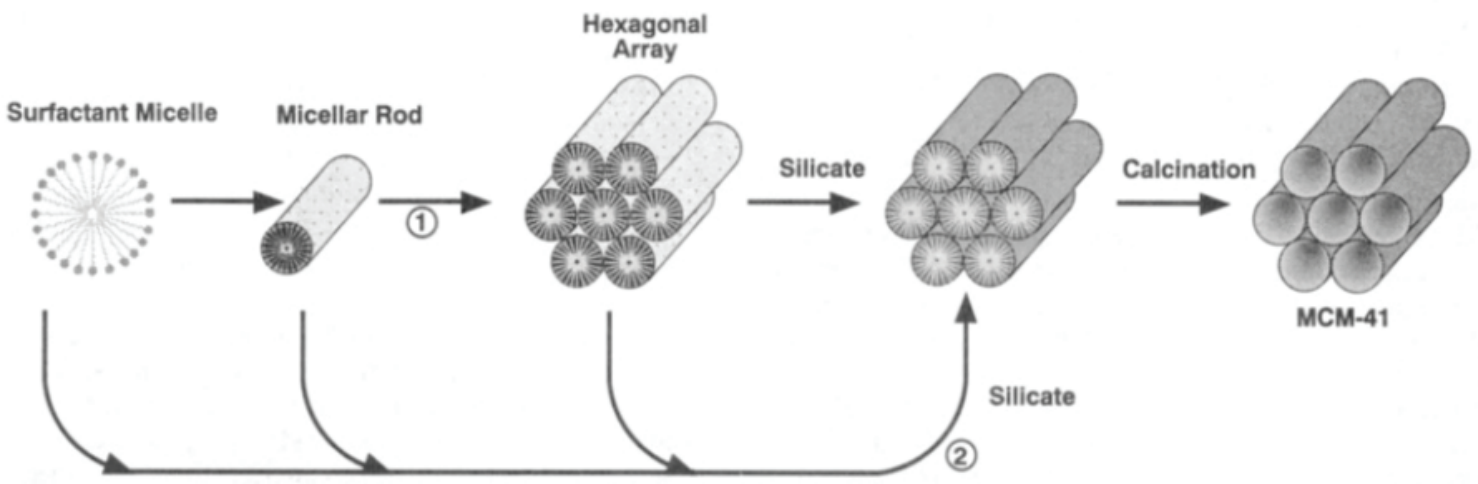

Figure 4: Mechanism of formation and structure of MCM-41 [66]. Reprinted with permission from Ref. [66]. Copyright $\odot$ 1992, American Chemical Society.

\section{Encapsulation of porphyrins in mesoporous molecular sieves}

There has been major interest in porphyrin encapsulation in mesoporous silicate sieves such as MCM-41 (Figure 4). These molecular sieves are comprised of a hexagonal array of rods with uniform mesopores and can be engineering to have a range of pore sizes from approximately $15 \AA$ to greater than $100 \AA$ and therefore have good potential for encapsulating catalysts such as porphyrins for heterogeneous catalysis [66,67].

One of the first reports of porphyrin encapsulated catalysts in MCM-41 was by Stein and co-workers who reported the preparation of $\mathrm{Mn}$ (III) meso-tetrakis(5trimethylammoniopentyl)porphyrin (TMAP) in MCM-41 in 1998 [68]. The encapsulation was successful using two different methods, namely hydrothermal synthesis and surfactant-porphyrin ion exchange with previously synthesised MCM-41. Interestingly, using UV-visible spectroscopy, the authors found that when the ion exchange mechanism was used, the porphyrin molecules formed dimers or aggregates while monomers were obtained when the porphyrin molecules were encapsulated during the synthesis procedure. The porphyrin could be metallated with $\mathrm{Cu}^{2+}, \mathrm{Ni}^{2+}$ and $\mathrm{Fe}^{2+}$ ions and it was found that no leaching of the porphyrin out of MCM-41 occurred. The peroxidase activity of the material was examined by using the catalyst for the peroxidation of the azo dye $\beta$-naphthol violet. The material synthesised by hydrothermal synthesis was found to be more active than that synthesised by ion exchange. This was attributed to the monomeric form of the porphyrin obtained during this synthetic procedure.

An example of an Fe(III) tetra-arylporphyrin encapsulated by Al-MCM-41 was reported by Nur and co-workers [69]. In this study Fe(III)-5,10,15,20-tetra-(4pyridyl)porphyrin (TPyP) was encapsulated in Al-MCM41 with an $\mathrm{Al} / \mathrm{Si}$ ratio of 20 , where the porphyrin was metallated after inclusion of TPyP into the mesopores of Al-MCM-41. The same porphyrin was also encapsulated 


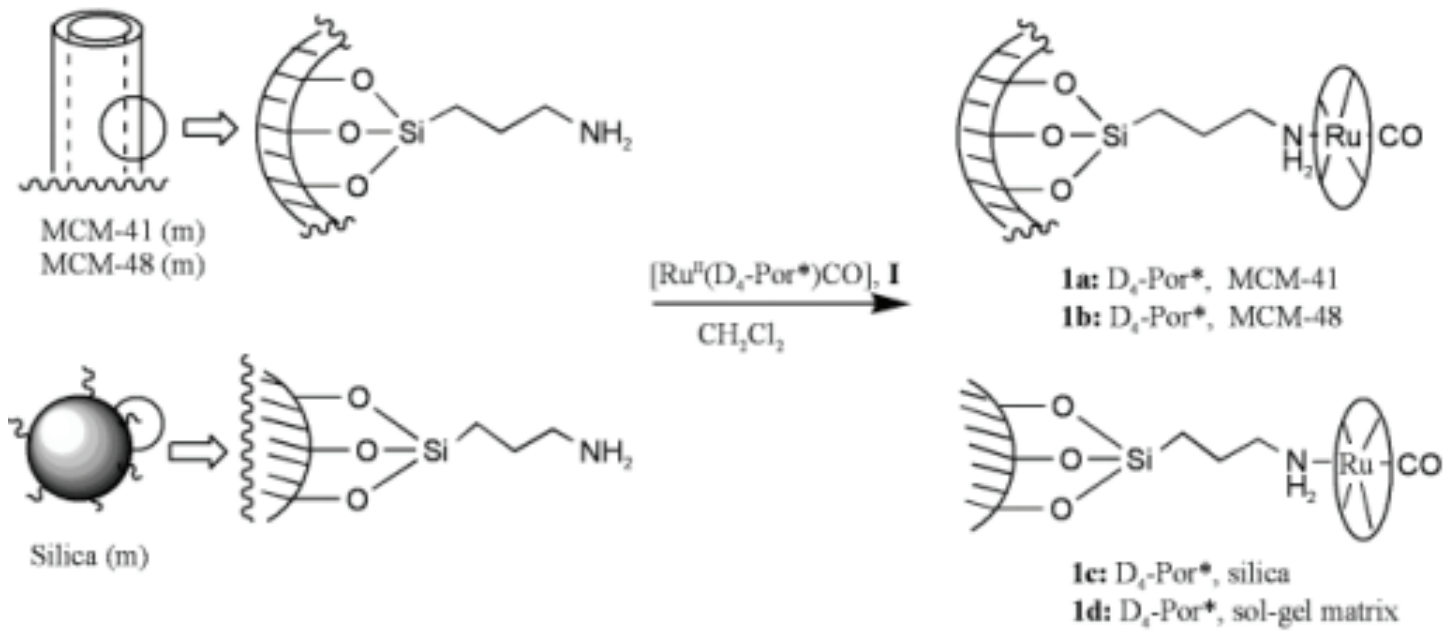

Figure 5: Immobilisation of $\mathrm{H}_{2}\left(\mathrm{D}_{4}-\right.$ Por $\left.^{\star}\right)$ onto MCM-41 and MCM-48 (top) and silica surfaces (bottom) [77]. Reprinted with permission from Ref. [77]. Copyright (C 2002, Royal Society of Chemistry.

in poly(methacrylic acid) (PMAA) by polymerising the methacrylic acid with a cross-linker around the Fe(III) TPyP. Both catalysts were characterised using UV-visible, PXRD and FTIR spectroscopies which confirmed successful encapsulation. The oxidation capabilities of the synthesised catalysts were investigated using the oxidation of benzene to phenol by $\mathrm{H}_{2} \mathrm{O}_{2}$. It was found that both synthesised catalysts were more active than Fe(III) TPyP in solution, but Fe(III)TPyP@PMAA was more active than Fe(III)TPyP@Al-MCM-41. Fe(III)TPyP@Al-MCM41, however, exhibited better recyclability and it was hypothesised that this was due to leaching of Fe(III)TPyP out of the polymer material.

There are several further examples of synthetic Fe(III), $\mathrm{Co}(\mathrm{II}), \mathrm{Ru}(\mathrm{II}), \mathrm{Pd}$ and $\mathrm{Mn}$ (III) metalloporphyrins being encapsulated in molecular sieves such as MCM-41 [7072], and more recently MCM-48 [73] and SBA-15 [74,75], a mesoporous material in which the silica nanoparticles are arranged in a hexagonal array and have pores of $4.6-30$ $\mathrm{nm}[76]$. These materials were used to investigate a range of oxidation and epoxidation reactions, most commonly the oxidation of cyclohexene and styrene using $\mathrm{H}_{2} \mathrm{O}_{2}$ and PhIO as oxidants.

One interesting example was reported by Che and co-workers who synthesised a ruthenium chiral porphyrin immobilized on both MCM-41 and MCM-48 (which has a three-dimensional structure that can easily be functionalised) [77]. In this study $\mathrm{Ru}(\mathrm{II})$ 5,10,15,20-tetrakis-(1S,4R,5R,8S)-1,2,3,4,5,6,7,8-octahydro1,2,5,8-dimethanoanthracen-9-yl]porphyrin, $\mathrm{H}_{2}\left(\mathrm{D}_{4}\right.$-Por $\left.{ }^{\star}\right)$, was immobilised. This porphyrin had previously been shown to have excellent reactivity and enantioselectivity in solution but there were high costs involved in the separation of the catalyst from the reaction mixture. ${ }^{78}$ The porphyrin was immobilised onto the surface of the molecular sieve or onto silica by modifying the respective surfaces with 3-aminopropyltriethoxysilane (Figure 5). The porphyrin molecule was subsequently strongly coordinated to the amino group.

Theepoxidation of alkenes using 2,6-dichloropyridine$\mathrm{N}$-oxide as oxidant was investigated. It was found that the porphyrin supported on both the molecular sieves and silica surfaces had very good conversions (72-99\%) and excellent enantioselectivity (ee $\approx 70 \%$ for most substrates) except for the porphyrin immobilised on the silica surface (ee 43\%). Furthermore, it was demonstrated that the catalyst could be reused through two cycles with only a slight drop in conversion percentage and a slight decrease in the enantioselectivity. This demonstrated that immobilisation of the porphyrin catalyst onto a silica surface or encapsulation within a molecular sieve was effective in converting a homogeneous catalyst to a heterogeneous one.

While there are multiple examples of molecular sieves being used for encapsulation of a variety of synthetic tetraphenylporphyrins, there is, to date, only one reported example of Fe(III)PPIX being encapsulated in a molecular sieve, MCM-41, published by Nazari et al. in 2005 [79]. Fe(III)PPIX was directly encapsulated into the pores of MCM-41 using micelles of cetyltrimethylammonium bromide both as a solvent for Fe(III)PPIX and as a template for formation of MCM-41. Successful encapsulation was confirmed using $\mathrm{N}_{2}$ adsorption isotherms, XRD, FT-IR and solid-state UV-visible techniques. The activity of Fe(III) 

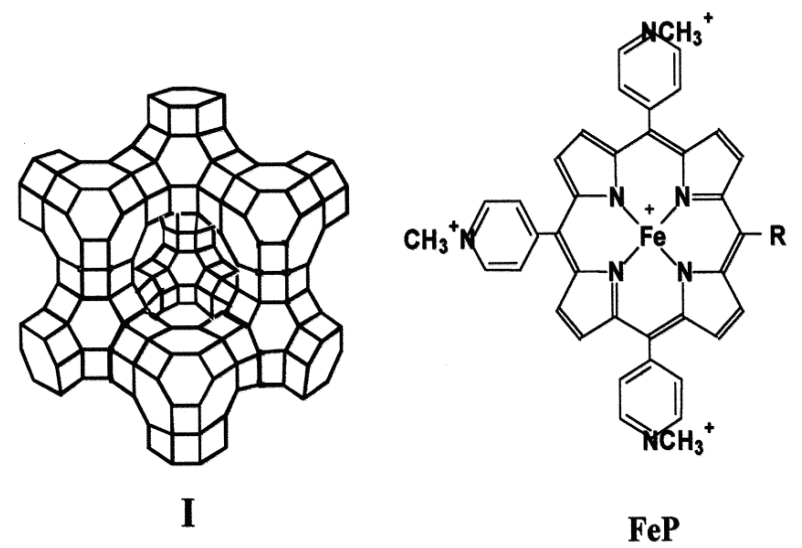

FeP 1

$[\mathrm{Fe}\{\mathrm{T}(4-\mathrm{N}-\mathrm{MePy}) \mathrm{P}\}]^{5+}$

$\mathrm{R}=4-\mathrm{N}-$ methylpyridyl

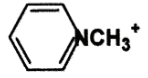

FeP 2

$[\mathrm{Fe}\{\mathrm{T}(4-\mathrm{N}-\mathrm{MePy}) \mathrm{MDCPP}\}]^{4+}$

$\mathbf{R}=$ 2,6-dichlorophenyl

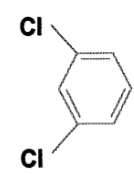

Figure 6: Encapsulation of two Fe(III) tetraphenylporphyrins into the cavities of zeolite NaX [82]. Reprinted with permission from Ref. [82]. Copyright $@ 2000$, Elsevier.

PPIX@MCM-41 was compared to the activity of MCM-41 impregnated with Fe(III) ions as well as HRP. The ability of Fe(III)PPIX@MCM-41 to oxidise phenol and guaiacol as well as catalyse the synthesis of indophenol was investigated. It was found that the Fe(III)PPIX@MCM-41 material was far more active than MCM-41 impregnated with $\mathrm{Fe}$ (III) ions, with a 100 -fold increase in relative initial rates. It was further observed that the Fe(III)PPIX@ MCM-41 material showed an increase in activity relative to Fe(III)PPIX in solution, but, as expected, the activity was lower than that of HRP.

\section{Encapsulation of porphyrins in zeolites}

Zeolites are microporous aluminosilicate materials built from $\mathrm{SiO}_{4}$ and $\mathrm{AlO}_{4}$ tetrahedra which have attracted great interest in the field of heterogeneous catalysis in recent years $[2,80]$. Zeolites contain molecular-sized channels and pores arranged in a three-dimensional network and can therefore exhibit both shape and size selectivity [80]. The most commonly used zeolites for porphyrin encapsulation are zeolites X (Z-X) and Y (Z-Y) and encapsulation of porphyrins into the cavity can be achieved using the method described by Balkus et al. for encapsulation of perfluorophthalocyanines, where the zeolite is built around the molecule [81]. Zeolite Y has been used with great success in the field of heterogeneous catalysis as the active component in catalysts for fluid catalytic cracking and contains a three-dimensional, twelve-membered ring system [80].

OneexampleofsyntheticFe(III)tetraphenylporphyrins being encapsulatedinZ-X cavitiesin a zeolite X was reported by Rosa et al. who used the method described by Balkus et al. to encapsulate Fe(III)TMPyP or Fe(III) 5-mono(2,6dichlorophenyl)-10,15,20-tris(4- $N$-methylpyridyl) porphyrin (Fe(III)P2) (Figure 6) [82]. The epoxidation of cyclooctene and hydroxylation of adamantane and cyclohexane by PhIO were investigated. Cyclooctene was selectively oxidised to cis-epoxycyclooctane by both the free and encapsulated porphyrins, however, the yield of cis-epoxycyclooctane was increased from $50 \%$ and $60 \%$, to $86 \%$ and $95 \%$ for Fe(III)TMPyP and Fe(III)P2, respectively. The hydroxylation of adamantane gave lower yields of 52\% and $45 \%$ for Fe(III)TMPyP and Fe(III)P2, respectively, and was selective for carbon 1. The hydroxylation of cyclohexane was also less efficient, and gave a yield of 50\% for Fe(III)TMPyP and an alcohol/ ketone ratio of approximately 10 . In both cases the encapsulated Fe(III)TMPyP and Fe(III)P2 were more active than the unencapsulated porphyrins in solution.

Moghadam et al. encapsulated Mn(III)TMPyP into zeolite $\mathrm{X}$ and $\mathrm{Y}(\mathrm{NaX}$ and $\mathrm{NaY}$ ) by synthesising the zeolite around the porphyrin [83]. The materials obtained were characterised by UV-visible, PXRD, FT-IR and neutron activation analysis. Interestingly, PXRD analysis showed that encapsulation of the porphyrin has very little effect on the structure of both $\mathrm{NaX}$ and $\mathrm{NaY}$. It was found that the 


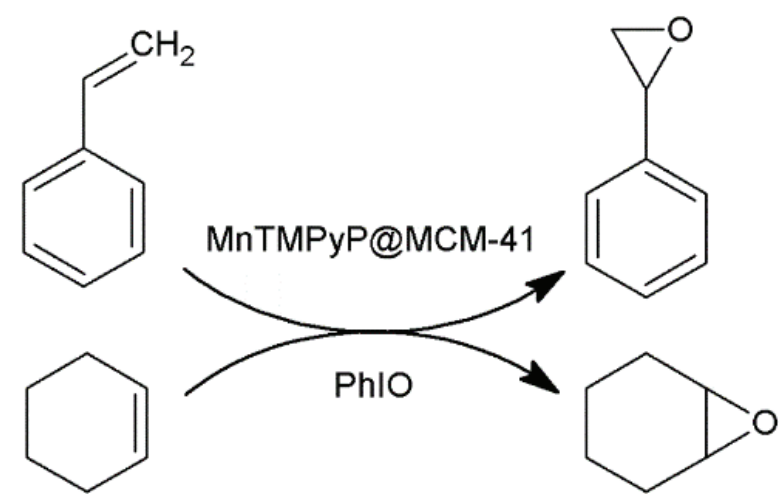

Scheme 4: Epoxidation of styrene (top) and cyclohexene (bottom) by PhIO catalysed by MnTMPyP@MCM-41 and MnTMPyp@DMY. A possible mechanism for this reaction is shown in Scheme 3.

loading of the porphyrin into NaY was almost double that in $\mathrm{NaX}$ and it was proposed that the difference was a result of the differing $\mathrm{Si} / \mathrm{Al}$ ratios present in the two frameworks. The catalytic activity of both catalysts was investigated by oxidising a variety of linear and cyclic alkenes using $\mathrm{NaIO}_{4}$. Reactions were conducted either under mechanical stirring or microwave irradiation. A decrease in yield with increase in size of the linear alkenes was observed, indicating the possibility of the material being used for shape selective catalysis.

Xia and co-workers encapsulated Mn(III)TMPyP penta-acetate in both mesoporous MCM-41 and DMY (a $\mathrm{NaY}$ zeolite) [73]. The porphyrin was encapsulated by soaking the zeolite in a solution containing the porphyrin. The potential of the porphyrin encapsulated materials as oxidation catalysts was investigated using the epoxidation of styrene and cyclohexene by PhIO (Scheme 4). It was found that the encapsulated porphyrin was more effective than the native porphyrin in solution and that the material could be reused through multiple cycles, although prolonged reuse resulted in a loss of activity.

Another example of an Fe(III) synthetic porphyrin being encapsulated in a $\mathrm{NaY}$ zeolite was reported by Karimipour et al. [84]. In this study [meso-tetrakis(3pyridyl)porphyrinato]iron(III) chloride was encapsulated in $\mathrm{NaY}$ in the same manner as the previous examples and characterised using PXRD, UV-visible spectroscopy, FT-IR and atomic absorption (AA) spectroscopy and scanning electron microscopy. The epoxidation of cyclohexene and other alkenes by (diacetoxyiodo)benzene $\left(\mathrm{PhI}(\mathrm{OAc})_{2}\right)$ was used to probe the catalyst activity. It was found that the catalyst showed good activity (yields of 16\%-94\%) and that it could be recovered and reused through multiple cycles. The oxidation of 4-nitrobenzyl alcohol as well as a 1,4-dihydropyridine were investigated and very high yields were obtained in both cases ( $97 \%$ and $100 \%$, respectively).
To date, there are no examples of native FePPIX being encapsulated into zeolites used for heterogeneous catalysis reported in the literature.

\section{Immobilisation of porphyrins in gels}

The term gel is a broad description of any gelating species that involves non-covalent interactions when formed $[85,86]$. Gels are solid-like and do not flow like a liquid, and can therefore be used to encapsulate porphyrins to form a heterogeneous catalyst [85].

In 1994 Iamamoto et al. reported the encapsulation of $\mathrm{Fe}(\mathrm{III})$ and $\mathrm{Mn}$ (III) tetra-2,6-dichlorophenylporphyrin (Fe(III)TDCPP and Mn(III)TDCPP) and Fe(III) and Mn(III) tetraphenylporphyrin encapsulated in an imidazole propyl gel and silica gel [87]. The porphyrin containing material was synthesised by stirring the metalloporphyrin with the gel materials and filtering off the product. Characterisation was performed by UV-visible and EPR spectroscopies. The oxidation of cyclohexane to cyclohexanol by PhIO was studied and compared to the porphyrins in solution. It was found that the supported catalysts were more active than the catalysts in solution, and that Mn(III)TDCPP@ imidazole propyl gel was the most active catalyst, giving the highest yield of cyclohexanol (67\%). It was also found that the material could be recycled and reused for up to five cycles.

Battioni and co-workers reported the synthesis of a silica-based gel using the sol-gel process constructed by hydrolysis and polycondensation, or co-condensation of $\mathrm{Fe}(\mathrm{III})$ and $\mathrm{Mn}$ (III) meso-tetrakispentafluorophenylporphyrins derivatised with a trifluorosilyl functional group and tetraethoxysilane [88]. The oxidation of heptane, cyclohexane and adamantane using PhIO and epoxidation of cyclohexene using t $\mathrm{BuOOH}$ was investigated. It was found that these materials were efficient catalysts and showed a size selective oxidation of the larger substrate.

There are many examples of synthetic porphyrins being encapsulated in gels for a variety of applications, however there are fewer examples of these materials being used as heterogeneous oxidation catalysts [89-94]. Most of these examples make use of silica-based gels as the support for the porphyrin. There are four examples of Fe(III)PPIX being encapsulated in gel materials [9598]; however, two of these examples are water-soluble nanogels and are therefore not heterogeneous catalysts $[95,98]$. 
A<smiles>N[C@@H](CCCCNC(=O)OCC1c2ccccc2-c2ccccc21)C(=O)O</smiles>

1

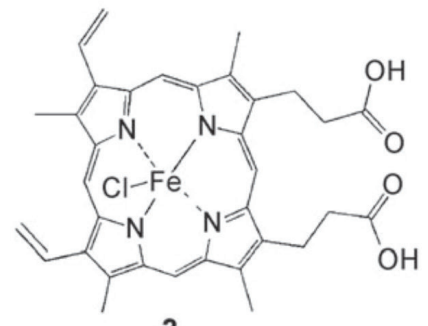

3

B

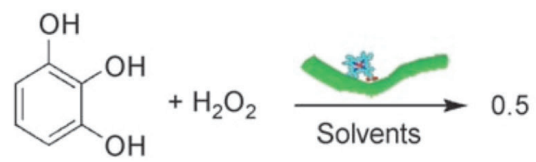

S: pyrogallol<smiles>O=C(O)N[C@@H](COC1c2ccccc2-c2ccccc21)C(=O)O</smiles>

2<smiles>NC(Cc1c[nH]cn1)C(=O)O</smiles>

4
$1+2+3$ (with or without) 4
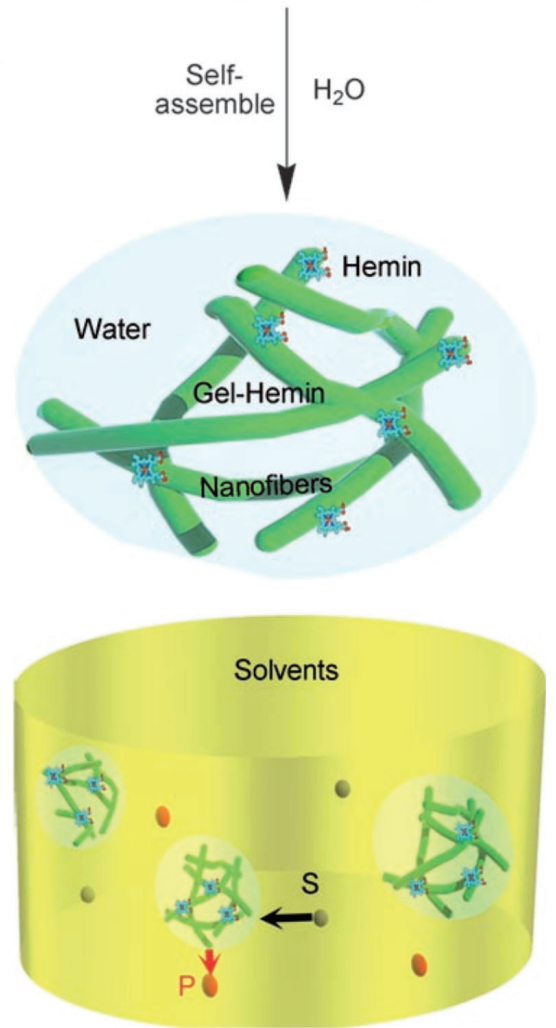

Scheme 5: (A) Derivatised amino acids (1 and 2), haemin (3) and histidine (4) used to synthesise supramolecular hydrogels; B) Peroxidation of pyrogallol to purpurogallin ( $\mathrm{S}=$ substrate (pyrogallol) $\mathrm{P}=$ product (purpurogallin), and solvent = aqueous buffer solution ( $0.01 \mathrm{M}$ phosphate, pH 7.4,) or toluene [97]. Reprinted with permission from Ref. [97]. Copyright @ 2007, John Wiley and Sons.

The first report of Fe(III)PPIX immobilised in a supramolecular hydrogel for application in heterogeneous catalysis was published by Wang et al. in 2007.97 Haemin was directly incorporated into the hydrogel (formed with two derivatised amino acids) by including it in the reaction mixture, which self-assembled to form a haemin@ hydrogel material (Scheme 5A). TEM with EDX was used to show that the haemin was localised along the surface of the nanofibers that made up the hydrogel, rather than being encapsulated in the nanofibers themselves. For comparison, the haemin@gel material was synthesised with and without a histidine residue, to investigate the effect of a potential axial ligand to coordinate to the iron centre of Fe(III)PPIX. Importantly, it was found using UV-visible spectroscopy that haemin was in a monomeric form when encapsulated in the gel.

The peroxidatic potential of the material was investigated by determining the ability of the haemin@ gel material to catalyse the oxidation of pyrogallol to purpurogallin (Scheme 5B) in an aqueous solution and organic solvent (toluene). It was found that the encapsulated haemin was drastically more active than native haemin in both aqueous and organic solutions. Interestingly, the haemin@gel prepared in the presence of histidine was more active than that prepared in the absence of histidine and the increase in activity relative to haemin was greater in the organic solvent compared to aqueous solution. This study indicated that gel encapsulation is a viable method for preparing haem-based heterogeneous oxidation catalysts.

This work was extended in a study in 2008, where the activities of synthetic derivatives of haem encapsulated in the same hydrogel were compared to that of native haemin (Figure 7) [96]. The activity was assayed using the same reaction, oxidation of pyrogallol to purpurogallin in an aqueous buffer as well as toluene, used in the initial study. It was found that the synthesised porphyrins were all far more active than native haemin, with the most active derivative (6) in toluene reaching $90 \%$ of the activity of HRP in aqueous buffer. 

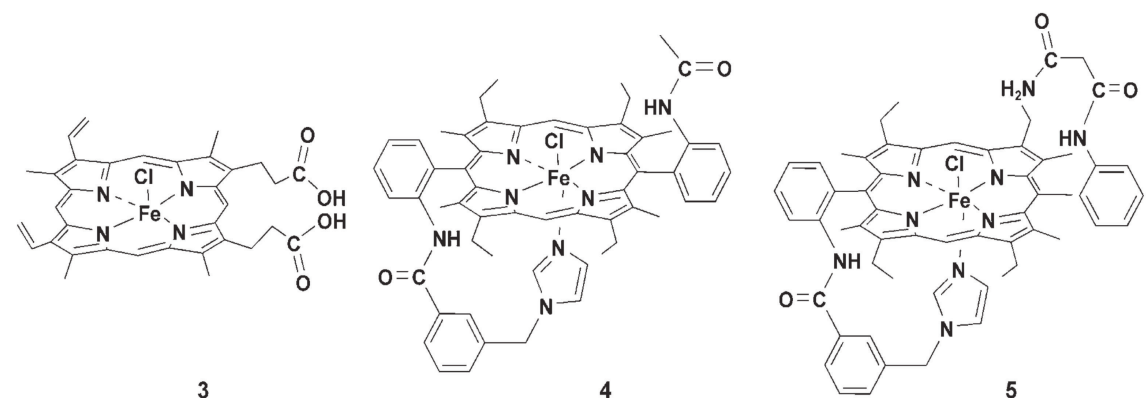

4

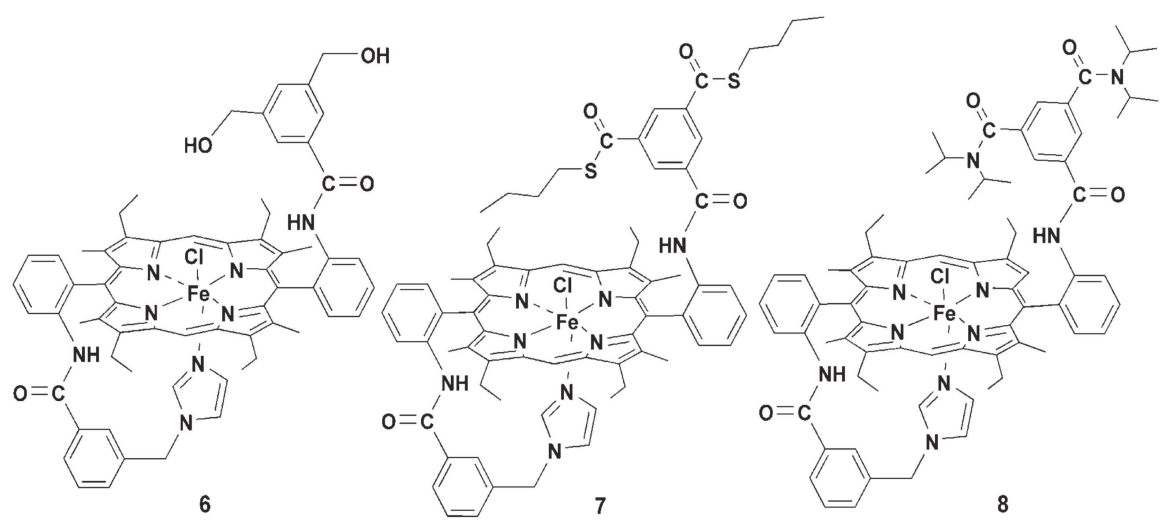

Figure 7: Structures of haemin (3) and synthetic derivatives (4 - 8) used in the study by Wang et al. [96]. Reprinted with permission from Ref. [96]. Copyright $\odot 2008$, John Wiley and Sons.

\section{Encapsulation of synthetic porphyrins in metal-organic frameworks}

Metal organic materials (MOMs) are a broad class of materials which have, in their most basic form, metal centre(s) coordinated to organic linkers in order to create a material which has a variety of functionalities [99-101]. This class of materials can be sub-divided into four subclasses; namely (i) coordination complexes, (ii) metalorganic polyhedra (MOPs), (iii) metal-organic frameworks (MOFs) and (iv) metal-organic gels (MOGs) [50]. MOFs have attracted a lot of interest in the field of porphyrin heterogeneous catalysis as they have the potential to overcome common problems identified with other solid supports by providing a well-defined environment for catalyst confinement in isolated active sites in which substrate access to the catalytic sites is also controlled, thereby creating robust and efficient catalysts [1,102104]. There is a large field of work which involves using metalloporphyrins as linkers for the construction of MOFs for application as heterogeneous catalysts, but they are not discussed in this review as they do not involve the encapsulation of a porphyrin. A number of excellent reviews on this subject are available for interested readers [105-107].

Encapsulation of metalloporphyrins into a MOF framework can either be done post-synthetically or in situ during the synthesis process [50]. When encapsulating the porphyrin in situ, a method commonly termed the 'ship-in-a-bottle process', the framework is built around the porphyrin in the reaction mixture, thereby locking the porphyrin in place and preventing the porphyrin leaching out of the framework through multiple catalytic cycles. The encapsulated porphyrin can either be pre-metallated, the porphyrin metallated in situ during the synthesis of the porphyrin@MOF material or incorporation of the metal centre can be done post-synthetically by exposing the synthesised porphyrin@MOF material to a solution of the desired metal ions.

The first example of a metalloporphyrin being encapsulated in a metal-organic material (MOM) was reported by Hupp et al. in 1999 who encapsulated a Zn porphyrin in a Zn containing thin film material [108]. The first reported study of a synthetic tetraphenylporphyrin being encapsulated in a MOF was reported by Eddaoudi and co-workers in 2008 [109]. In this report the tetra( $p$ toluenesulfonate) salt of TMPyP (Figure 8a), was encapsulated in a zeolite-like MOF constructed from 

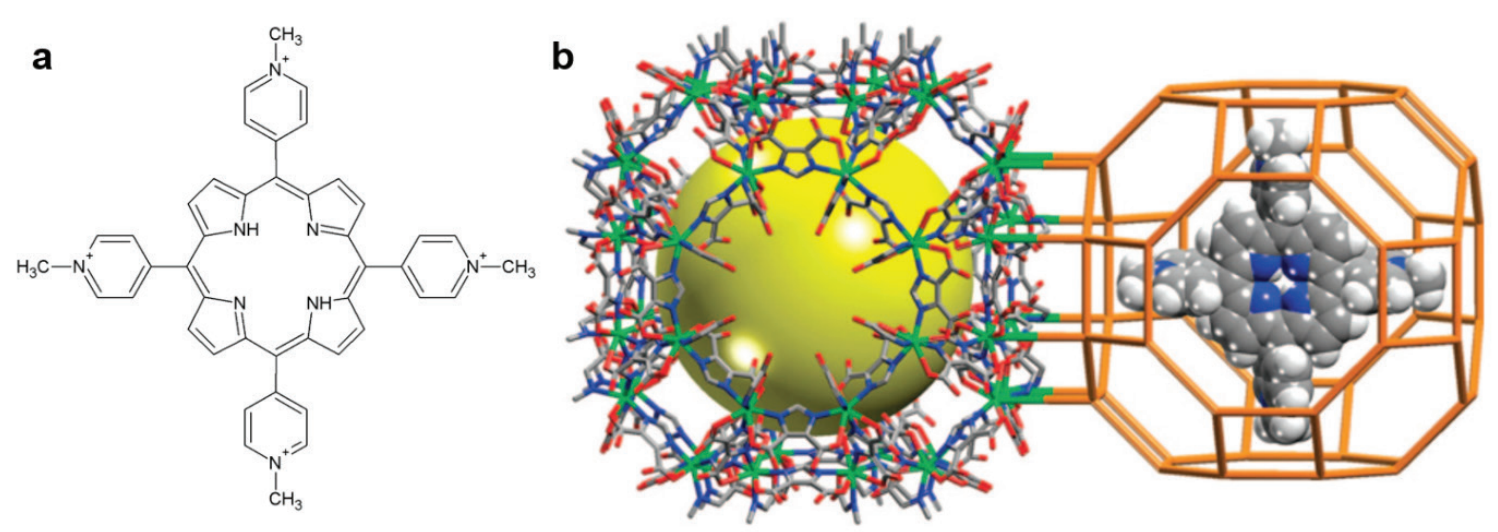

Figure 8: (a) Structure of TMPyP; (b) Structural representation of rho-ZMOF encapsulating TMPyP [109]. Reprinted with permission from Ref. [109]. Copyright (C) 2008, American Chemical Society.

$\operatorname{In}\left(\mathrm{NO}_{3}\right)_{3} \cdot \mathrm{xH}_{2} \mathrm{O}$ and 4,5-imidazoledicarboxylic acid ( $\mathrm{H}_{3} \mathrm{ImDC}$ ) (rho-ZMOF) (Figure $8 \mathrm{~b}$ ). This framework is negatively charged and therefore required a cationic porphyrin molecule for successful encapsulation. Attempts to encapsulate neutral and anionic porphyrins were unsuccessful. The material was characterised using solid-state UV-visible spectroscopy on washed crystals and the presence of the Soret band confirmed encapsulation of $\left[\mathrm{H}_{2} \mathrm{TMPyP}\right]$ into the truncated octahedral cage of the MOF. Single crystal XRD of crystals obtained was not possible. This was attributed to the lowering of the inherent symmetry of TMPyP. The porphyrin was successfully postmetallated with $\mathrm{Mn}$ (III), $\mathrm{Co}(\mathrm{III}), \mathrm{Cu}(\mathrm{II})$ and $\mathrm{Zn}$ (II) ions and was confirmed using solid-state UV-visible spectroscopy.

The oxidation capability of the synthesised Mn(III) TMPyP@rho-ZMOF was investigated using the oxidation of cyclohexane to cyclohexanone via cyclohexanol. The oxidising agent ${ }^{\mathrm{t}} \mathrm{BuOOH}$ was used in 2:1 molar ratio of ${ }^{\mathrm{t}} \mathrm{BuOOH}$ to cyclohexane. The conversion of reactants to a mixture of products was $91.5 \%$, where the major product (approx. 60\%) was cyclohexanone. A turnover number of 23.5 was obtained after $24 \mathrm{~h}$ and the catalyst retained its activity through eleven consecutive cycles.

One of the most significant contributions to the field of metalloporphyrin@MOFs was published by Larsen et al.in 2011 [110]. In this study a collection of metalloporphyrins were encapsulated in the HKUST-1 framework, a $\mathrm{Cu} / \mathrm{Zn}$ framework constructed from three connected trimesic acid (benzene-1,3,5-tricarboxylic acid, BTC) ligands and four connected $\mathrm{Cu} / \mathrm{Zn}$ carboxylate $\left[\mathrm{Cu} / \mathrm{Zn}_{2}(-\mathrm{COO})_{4}\right]$ square paddlewheels which affords a framework with $t b o$ topology. Frameworks with this topology have threedistinct cages; namely rhombihexahedral, octahemioctahedral, and tetrahedral. The octahemioctahedral cage (diameter $13 \AA$ ), however, is the only cage suitable for porphyrin encapsulation owing to its larger size and volume relative to the other cages.

In this study $\mathrm{Fe}(\mathrm{III})$ and $\mathrm{Mn}(\mathrm{III})$ tetrakis(4sulfonatophenyl)porphyrin (Fe(III)/Mn(III)TSPP) were encapsulated in $\mathrm{Cu} / \mathrm{Zn}$-HKUST-1 (Figure 9). A loading of $66 \%$ of the available cavities was found using ICP-OES when the material was synthesised in a saturated porphyrin solution, and the loading ranged from 33\%-66\% when changing reaction conditions. Unlike the study by Eddaoudi and co-workers, in this study single crystal X-ray data was obtained. This allowed the exact position of the porphyrin in the MOF to be determined (Figure 9 bottom). The phenyl rings extended into the adjacent cavities, thereby 'locking' the porphyrin into place and reducing the extent of disorder. The porphyrin molecule was, however, positionally disordered over the three equivalent orientations of the cavity. The loading calculated using the ICP-OES data was supported by the single crystal XRD data. Successful encapsulation was further confirmed using solid state UV-visible spectroscopy.

The oxidation capabilities of FeTSPP@Cu-HKUST-1 were investigated using the oxidation of 2,2'-azino-bis(3ethylbenzothiazoline)-6-sulphonic acid (ABTS) to ABTS $\bullet+$ by $\mathrm{H}_{2} \mathrm{O}_{2}$ (Scheme 6). The activity was compared to horse heart metmyoglobin (hh-metMb), MP-11, homogeneous Fe(III)TSPP and Cu-HKUST-1. It was found that the initial rate of ABTS oxidation catalysed by the synthesised material was significantly lower than that of hh-metMb, MP-11 and homogeneous Fe(III)TSPP, however, the overall conversion was comparable to that of MP-11 and homogeneous Fe(III)TSPP. The recyclability was tested over three cycles and it was found that while the conversion percentage remained constant, there was a significant decrease in the rate of each successive reaction. 
<smiles>CCn1/c(=N\N=c2\sc3cc(S(=O)(=O)O)ccc3n2CC)sc2cc(S(=O)(=O)[O-])ccc21</smiles>

ABTS<smiles></smiles>

ABTS $\bullet+$

Scheme 6: Fe(III) porphyrin catalysed oxidation of ABTS to ABTS ${ }^{\bullet+}$ by $\mathrm{H}_{2} \mathrm{O}_{2}$.
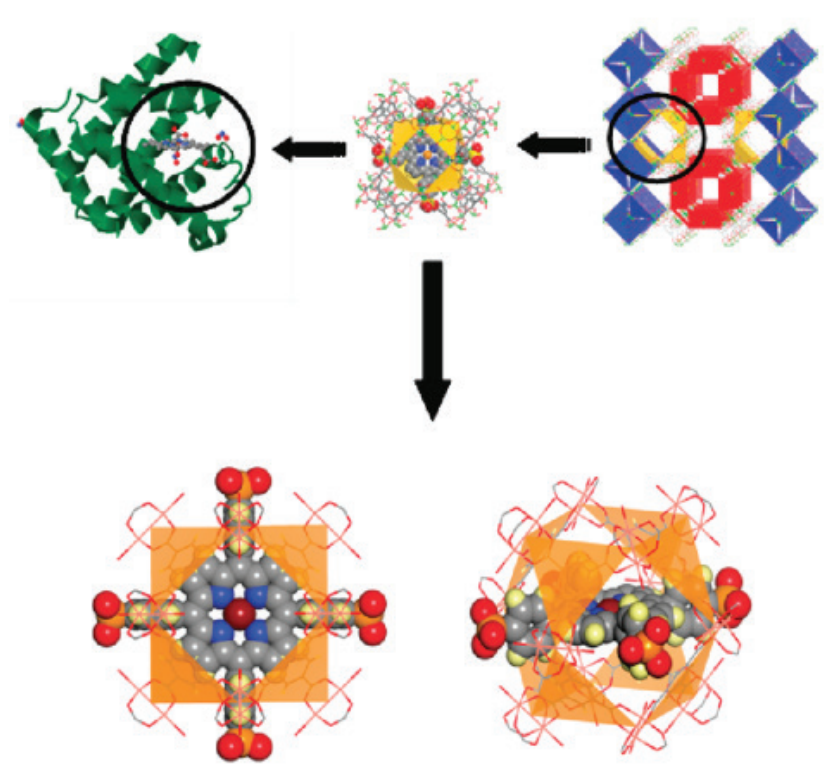

Figure 9: (Top) Encapsulation of Fe(III)/Mn(III)TSPP into octahemioctahedral cage of HKUST-1 framework and its structural resemblance to a haemoprotein; (bottom) two of the three equivalent orientations of $\mathrm{Fe}(\mathrm{III}) / \mathrm{Mn}$ (III)TSPP encapsulated in HKUST-1 [110]. Reprinted with permission from Ref. [110]. Copyright (C) 2011, American Chemical Society.

This group also further expanded the investigation to study the photophysical properties of $\mathrm{Zn}$ (II)TMPyP encapsulated in Zn-HKUST-1 [111]. The structure of this porphyrin encapsulating complex was similar to that of $\mathrm{Fe}(\mathrm{III}) / \mathrm{Mn}$ (III)TSPP in CuHKUST-1 as reported by Larsen et al [110]. While no heterogeneous catalysis experiments were conducted with this material, it is interesting to note that the 'locking' of the porphyrin in place as observed in the previous study gave rise to a well resolved fluorescence emission spectrum as well as in increase in the emission lifetime of Zn(II)TMPyP.

In 2012, Zawarotko and co-workers published two significant studies on the encapsulation of metalloporphyrins in MOFs [112,113]. In the firststudy, Fe(III) (porph@MOF-4), Co(II) (porph@MOF-5), Mn(III) (porph@ MOF-6), Ni(II) (porph@MOF-7), Mg(II) (porph@MOF-8) and
Zn(II) (porph@MOF-9), M(II)TMPyP, were encapsulated in MOFs constructed with BTC and the corresponding metal salt (namely chlorides in the case of Fe(III), $\mathrm{Co}(\mathrm{II}), \mathrm{Mn}$ (III), acetates in the case of $\mathrm{Ni}(\mathrm{II})$ and $\mathrm{Mg}$ (II) and nitrate in the case of $\mathrm{Zn}(\mathrm{II})$ ) [112]. Crystal structures were obtained for all porphyrin@MOF materials obtained. While it was found that deviation from the ideal HKUST-1 structure occurred in some cases, the mode of encapsulation was retained throughout with the pyridyl rings of the porphyrin locked in the square windows of the framework.

Porph@MOF-4, -5 and -6 displayed a structure isostructural with the HKUST-1 framework with similar unit cell dimensions to previously reported porphyrin encapsulating MOFs and tbo topology (Figure 10a) [110]. Porph@MOF-7 had a unit cell dimension that was larger than that reported for the previous frameworks $(a=27.478$ $\AA$, compared to $\mathrm{a}=26.594 \AA$ ) $)$. The synthesis of porph@ MOF-9 resulted in significant change to the structure of the previous porph@MOFs synthesised, with a change in space group from $\mathrm{Fm}-3 \mathrm{~m}$ to $\mathrm{Cmmm}$ and a novel 3,3,4,4,6-connected net (Figure 10b).

The epoxidation of alkenes using ${ }^{\mathrm{BuOOH}}$ as an oxidant was used to investigate the catalytic activity of porph@MOF-4. The oxidation of styrene was completed to about $\sim 85 \%$ after $10 \mathrm{~h}$, with the major products identified as styrene oxide and benzaldehyde (30 and 57\%, respectively) compared to only $\sim 35 \%$ using the equivalent amount of $\mathrm{Fe}(\mathrm{III}) \mathrm{TMPyP}$ in solution. Porph@MOF-4 showed good size selectivity compared to Fe(III)TMPyP in solution (Figure 11) and this was attributed to the increase in steric strain with the addition of bulky groups. When the recyclability of this catalyst was tested, it was found that there was a drop in the conversion of substrate to products for cycles two and three ( $\sim 70 \%$ and $60 \%$, respectively), but the conversion percentage remained constant for the following three cycles.

The second study published by Zawarotko and co-workers in 2012 involved the encapsulation of $\mathrm{Cd}(\mathrm{II})$ TMPyP cations in a MOF constructed from biphenyl-3,4,5tricarboxylate (BPT) and $\mathrm{CdCl}_{3}$, namely porph@MOF-10 
a

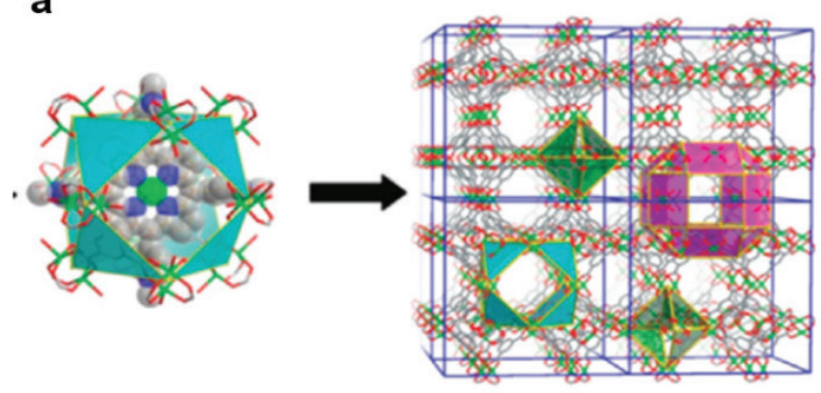

b

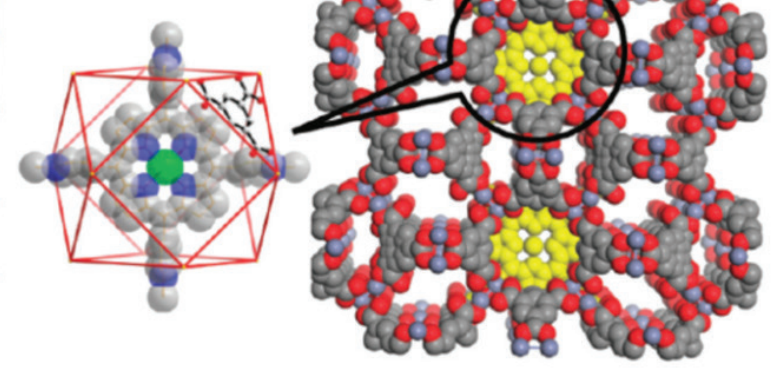

Figure 10: (a) TMPyP encapsulated in the octahemioctahedral cage of the HKUST-1 framework with pyridyl rings extending into adjacent cages (left) and the polyhedral cage framework of porph@MOF-4, -5, and -6 with three distinct cages (right); (b) TMPyP located in an octahemioctahedral cage of porph@MOF-9 (left) and space-fill model of porph@MOF-9 projected along the c-axis showing the novel 3,3,4,4,6-connected net [112]. Reprinted with permission from Ref. [112]. Copyright @ 2012, American Chemical Society.

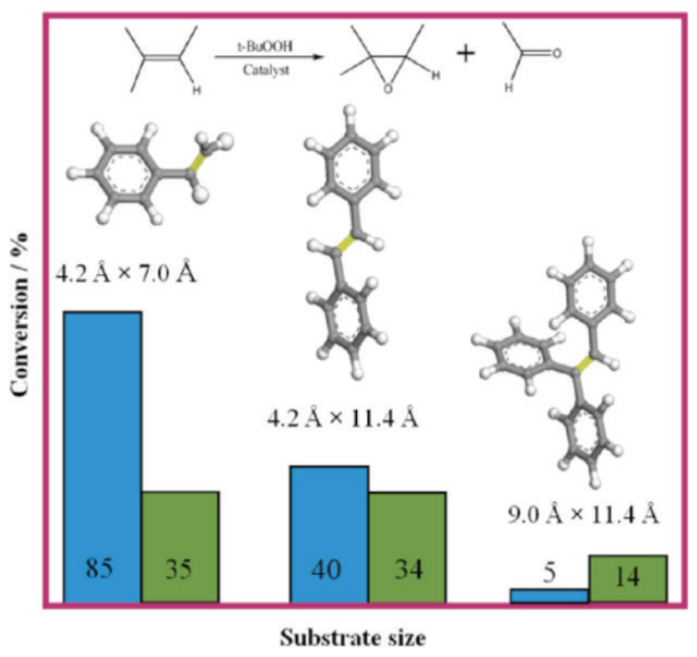

Figure 11: Epoxidation of alkenes by porph@MOF-4 (blue) and Fe(III) TMPyP (green) showing good size-selective activity by porph@MOF4 [112]. Reprinted with permission from Ref. [112]. Copyright () 2012, American Chemical Society.

[113]. Single crystals of porph@MOF-10 were obtained and it was found that the framework itself was anionic, with cationic TMPyP and $\mathrm{H}_{3} \mathrm{O}^{+}$ions encapsulated in the channels. The framework contained two square channels, with TMPyP being encapsulated exclusively in the larger channel (dimensions 12.6 x $12.6 \AA^{2}$ ) (Fig 12; channel B). Contrary to other examples of porphyrin encapsulation in MOFs, significant interactions between the porphyrin and the MOF framework were found. There were $\pi \cdots \pi$ interactions between the pyridyl groups of porphyrin and phenyl rings of BPT as well as hydrogen bonds between the methyl groups of the cationic pyridyl of the porphyrin and the $\mu-\mathrm{Cl}$ ligands connected to the $\mathrm{Cd}$ ions of the framework.
It was found that crystals of porph@MOF-10 could undergo post-synthetic modification and the $\mathrm{Cd}$ ions in TMPyP and the framework metal ions (partially in the case of $\mathrm{Cu}$ ) could be exchanged for $\mathrm{Mn}$ or $\mathrm{Cu}$ by soaking the crystal in a solution of $\mathrm{MnCl}_{2}$ or $\mathrm{CuCl}_{2}$ forming MnTMPyP@ MOF-10-Mn and CuTMPyP@MOF-10-CdCu, respectively. The catalytic activity of these materials was assessed using the oxidation of trans-stilbene with ${ }^{\mathrm{t}} \mathrm{BuOOH}$ as an oxidant. It was found that the original porph@MOF-10 material had very poor activity with a conversion of only $\sim 7 \%$; however, both MnTMPyP@MOF-10-Mn and CuTMPyP@MOF-10$\mathrm{CdCu}$ showed good activities with conversions of $75 \%$ and $79 \%$, respectively with stilbene oxide and benzaldehyde as the major products. Both the catalysts showed good selectivity for stilbene oxide (56\% and 61\%, respectively) and were recycled through six cycles with minimal loss in catalytic activity.

Zhang et al. further investigated the potential of Mn(III)TMPyP as an oxidation catalyst by encapsulating it in two further Cd MOFs, constructed from BTC and [1,1',3',1'-terphenyl]-4,4',5'-tricarboxylate (TPT), respectively [114]. These structures were termed porph@ MOF-12 and -13, respectively, and the crystal structures of both were determined. The framework constructed from Cd and BTC did not give rise to the HKUST- 1 type structure previously seen when this ligand was used, but rather a framework which contained hexagonal channels with two different size channels giving rise to a 3D honeycomb-like structure with a topology $m z z$ (Figure 13a). The porphyrin moiety exclusively was encapsulated in one channel with diameter 17.6 A. Contrary to previous examples of Mn(III) TMPyP encapsulation, in the case of porph@MOF-13, the porphyrin was encapsulated in all the square channels formed by this framework (Figure 13b) with rtl topology. Short range attractive forces similar to those described by 


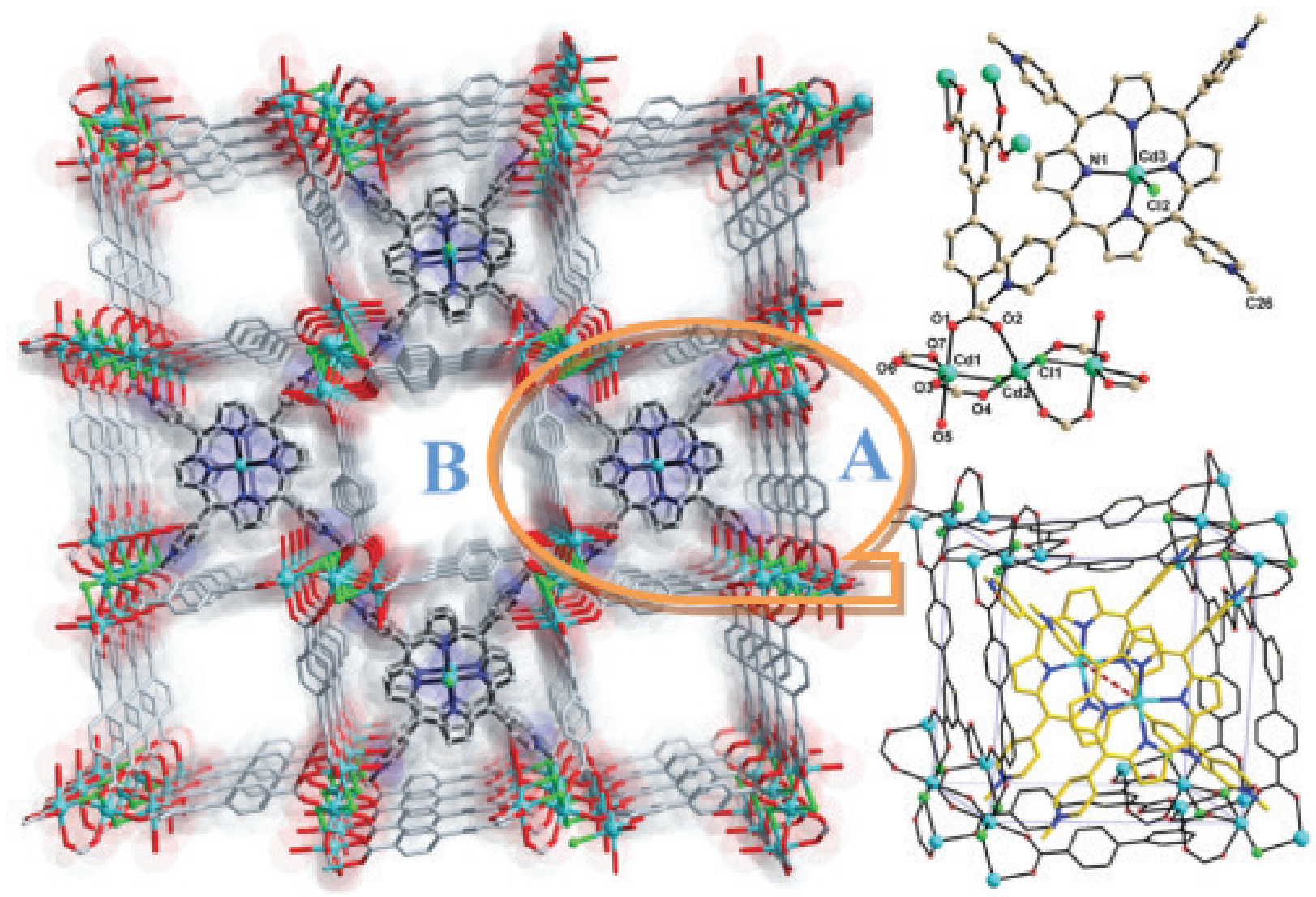

Figure 12: Projection of the structure of porph@MOF-10 along the c axis showing Cd(II)TMPyP in channel B (orange circle); (upper right) Components of the framework and Cd(II)TMPyP cations in porph@MOF-10; (lower right) Illustration of Cd(II)TMPyP cations trapped in square channels of porph@MOF-10 [113]. Reprinted with permission from Ref. [113]. Copyright @ 2012, American Chemical Society.

Zawarotko and co-workers in 2012 were also found to be present [113].

It was found that porph@MOF-12 could undergo postsynthetic modification and the $\mathrm{Cd}$ ion could be exchanged for $\mathrm{Mn}$ by soaking the crystals in a solution of $\mathrm{MnCl}_{2}$. The catalytic activities of both Mn- and Cd-porph@MOF-12 were investigated by studying the oxidation of styrene and comparing it to Mn(III)TMPyP. It was found that Mn(III)porph@MOF was the most active catalyst, with a conversion of $61 \%$, compared to $45 \%$ and $5 \%$ conversion for Mn(III)TMPyP and Cd(II)-porph@MOF-12, respectively.

Qiu et al. encapsulated $\mathrm{Cu}(\mathrm{II})$ and $\mathrm{Mn}$ (II) mesotetrakis[4-(nicotinoyloxy)phenyl]porphyrin (TNPP) in a $\mathrm{Cu}$ MOF with $p c u$ topology containing paddlewheel nodes constructed from 1,1-bis-[3,5-bis(carboxy)phenyoxy] methane [115]. The same method of building the framework in a 'ship-in-a-bottle' fashion was employed in this study. Successful encapsulation was confirmed by ICP-AES, with a marked colour change upon encapsulation of the porphyrin compared to the native MOF, as well as a decrease in the BET surface area as obtained from $\mathrm{N}_{2}$ gas sorption isotherms after encapsulation. PXRD patterns confirmed retention of the structure of the framework after encapsulation and while the porphyrin molecule could not be resolved in the single crystal X-ray data, it was hypothesised that the porphyrin molecule would reside in the largest cage in the framework.

The oxidation of 3,5-di-tert-butylcatechol (DTBC) to the corresponding quinone using $\mathrm{H}_{2} \mathrm{O}_{2}$ as the oxidant was investigated (Scheme 7). The activities of $\mathrm{Cu}$ (II)TNPP@ MOF and Mn(III)TNPP@MOF were compared to the native MOF, as well as both porphyrins in solution.Cu(II)TNPP@ MOF showed the highest activity, whileMn(III)TNPP@MOF displayed lower catalytic activity compared to the native MOF framework. Both Cu(II)TNPP@MOF and Mn(III) TNPP@MOF were more active than their homogeneous counterparts. Cu(II)TNPP@MOF was successfully recycled four times without loss of catalytic activity.

In 2015 Ling et al. reported the encapsulation of $\mathrm{Fe}(\mathrm{III}) \mathrm{TCPP}$ in Cu-HKUST-1 which was then sequentially 

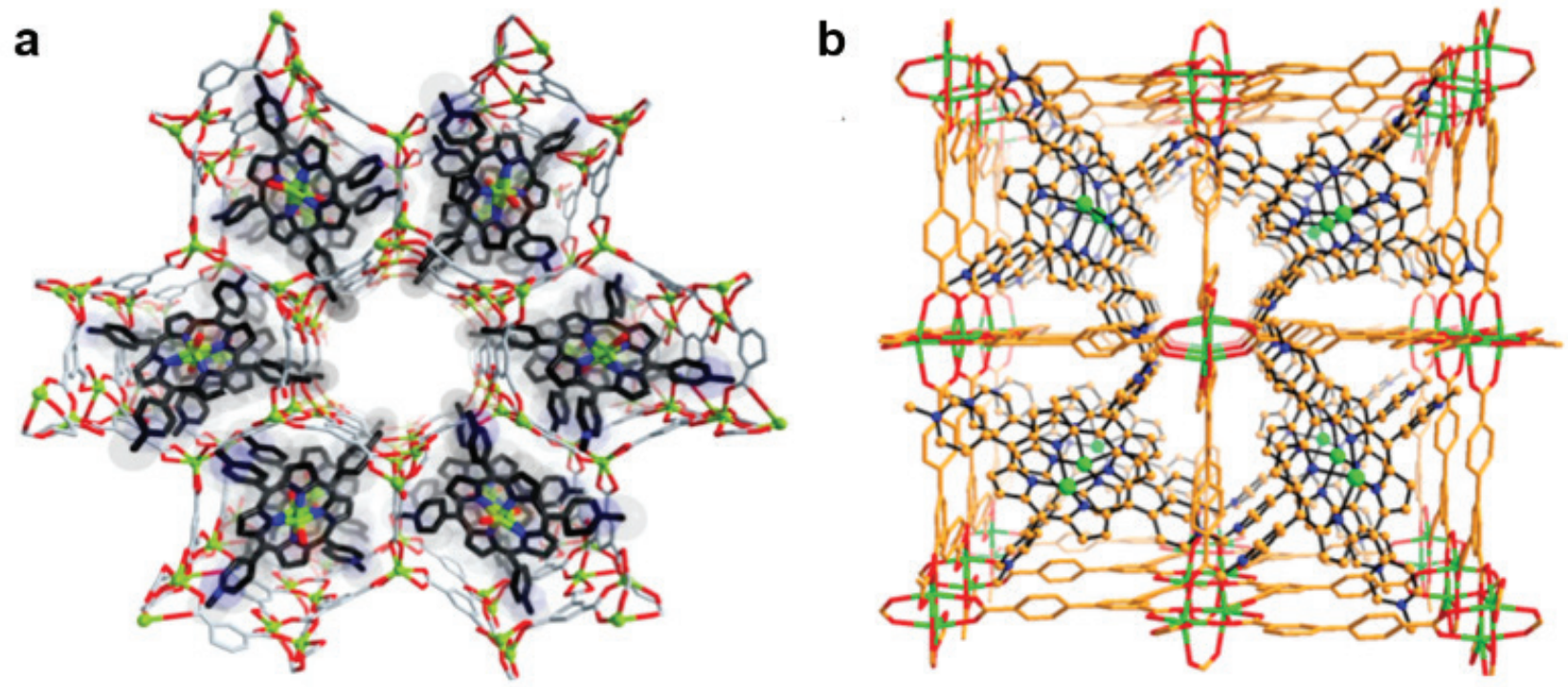

Figure 13: (a) Porph@MOF-12 showing the mzz topology and hexagonal channels; (b) Porph@MOF-13 viewed along the a-axis showing the square channels as well as MnTMPyP encapsulated in all channels [114]. Reprinted with permission from Ref. [114]. Copyright @ 2014, American Chemical Society.<smiles>CC(C)(C)c1cc(O)c(O)c(C(C)(C)C)c1</smiles>

Scheme 7: Oxidation of 3,5-di-tert-butylcatechol (DTBC) with $\mathrm{H}_{2} \mathrm{O}_{2}$ as an oxidant.

conjugated with streptavidin (SA), a nucleotide sequence recogniser, forming Fe(III)TCPP@Cu-HkUST-1-SA [116]. Successful synthesis of Fe(III)TCPP@Cu-HKUST-1 was confirmed using similar techniques previously used for metalloporphyrin@MOF catalysts, namely PXRD, UV-visible spectroscopy, and gas sorption experiments. This electrochemical sensor was designed to detect DNA using both the redox activity of Fe(III)TCPP@Cu-HKUST-1 as well as the allosteric switch of hairpin DNA. A hairpin DNA strand with a nucleotide sequence complementary to the target DNA and another sequence, which is suitable as a SA aptamer (small single-stranded nucleic acids that fold into a well-defined three-dimensional structure in the presence of the target) [117], were attached on a glassy carbon electrode (GCE) (Scheme 8). In the absence of the target, Fe(III)TCPP@CuHKUST-1-SA cannot bind to the DNA sequence on the electrode, however, upon binding of the target to the allosteric centre of the DNA, a conformation change occurs and the aptameric sequence becomes available for binding of FeTCPP@Cu-HKUST-1-SA. The encapsulated porphyrin can catalyse the oxidation of phenylenediamine (o-PD) to 2,2'-diaminoazobenzene in the presence of $\mathrm{H}_{2} \mathrm{O}_{2}$ giving an electrochemical response. This sensor could detect DNA at $0.48 \mathrm{fM}$ with the linear range of $10 \mathrm{fM}$ to $10 \mathrm{nM}$. It was found that Fe(III)TCPP@ Cu-HKUST-1-SA showed an enhancement of signal relative to native Fe(III)TCPP in solution.

All the metalloporphyin@MOF systems showed an increase in catalytic activity relative to the corresponding metalloporphyrins in solution, indicating that the process of encapsulation reduced the problems associated with homogeneous porphyrin catalysis. A review by Chakraborty et al. reports more detailed crystallographic information, such as morphology, space groups and topology of the abovementioned metalloporphyrin@MOF systems [50].

The HKUST-1 framework has been used extensively in this field, with a large number of crystal structures being reported for various tetraphenylporphyrins in MOFs containing the tbo topology. While the porphyrin itself is encapsulated in the large octahemioctahedral cage of the framework, the phenyl rings extend into the adjacent cages, thereby 'locking' the porphyrin in place. This reduces the extent of disorder present, which allows for single crystal X-ray data to be collected. Larsen et al. [110] suggested that the 'locking' of the porphyrin in this orientation created functionalisable and orientationally 


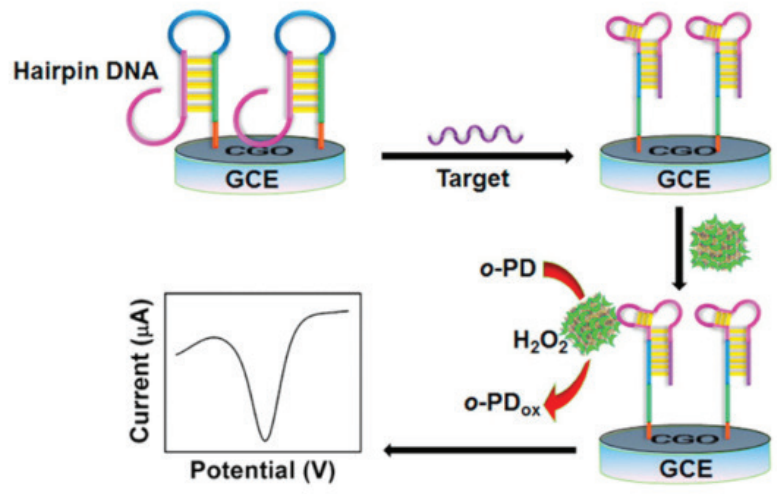

Scheme 8: Schematic representation of electrochemical target DNA detection via Fe(III)TCPP catalysed oxidation of o-PDA by $\mathrm{H}_{2} \mathrm{O}_{2}$ [116]. Reprinted with permission from Ref. [116]. Copyright (C) 2015, American Chemical Society.

specific proximal and distal haem pockets, similar to native haemoproteins. This contributes to the greater catalytic activity of these systems compared to porphyrin encapsulated in rhoZMOF, as reported by Eddaoudi and co-workers [109]. It should be noted that while this cage is large, the windows of the cage are not large enough to allow the metalloporphyrin to diffuse in and out of the framework. This means that the 'ship-in-a-bottle' approach is necessary to synthesise these compounds and presents the significant advantage of preventing leaching of the porphyrin out of the MOF when the catalyst is reused through multiple cycles.

When considering the crystal structures of metallporprhyrin@MOFs without the 'locking' feature, such as those reported by Zawarotko et al. [113] and Zhang et al. [114], short range forces were crucial to orientate the porphyrin within the framework. The ability of metalloporphyrins to be ordered within a MOFs has been postulated to be the primary reason for the increased activity of metalloporphyrin@MOFs compared to other solid supports [110].

\section{$7 \mathrm{Fe}(\mathrm{III}) \mathrm{PPIX}$ encapsulated in MOFs}

In contrast to the many studies where synthetic tetraphenylporphyrins have been encapsulated in MOFs, there are only a few reports of native FePPIX encapsulated in MOFs, all in the form of Fe(III)PPIX. The first Fe(III)PPIX encapsulating MOF was reported by Liu and co-workers. They encapsulated haemin into the well-known amino containing MIL-101(Al)- $\mathrm{NH}_{2}$ framework [118]. The aim of using this material was for the amino group to anchor the haem within the framework by axial coordination.
This study differs from others discussed so far in that encapsulation of haemin in the framework resulted in a structural change in the framework. It was shown that upon encapsulation of haemin the MIL-101(Al)- $\mathrm{NH}_{2}$ framework transformed to MIL-53(Al)- $\mathrm{NH}_{2}$ as seen by PXRD, SEM and the drastic reduction in BET surface area corresponding to the conversion from MIL-101(Al)- $\mathrm{NH}_{2}$ to MIL-53(Al)- $\mathrm{NH}_{2}$ (Figure 14a). A crystallographic change of this nature has been previously reported in the literature upon exposing MIL-101(Al)- $\mathrm{NH}_{2}$ to DMF for $12 \mathrm{~h}$ [119]. A loading of $1.02 \%$ of Fe into the framework was calculated using the $\mathrm{Al}$ to $\mathrm{Fe}$ ratio and a small decrease in BET surface area when comparing heamin@MIL-101(Al)- $\mathrm{NH}_{2}$ to MIL53(Al)- $\mathrm{NH}_{2}\left(407.6 \mathrm{~m}^{2} \cdot \mathrm{g}^{-1}\right.$ compared to $\left.464.5 \mathrm{~m}^{2} \cdot \mathrm{g}^{-1}\right)$ further confirmed the loading (Figure 14b).

The catalytic activity of this haemin@MIL-101(Al)- $\mathrm{NH}_{2}$ MOF was investigated using the chromogenic substrate 3,3',5,5'-tetramethyl-4,4'-diaminebiphenyl (TMB) which is known to be active in the presence of Fe(III)PPIX catalysts (Figure 15) [120,121]. It was shown that haemin@ MIL101(Al)- $\mathrm{NH}_{2}$ catalysed the oxidation of TMB, while the parent MOF brought about no reaction and haemin in solution only supported a slight reaction. It was shown that $\mathrm{pH} 5$ was the optimal $\mathrm{pH}$ for the reaction, and haemin@MIL-101(Al)- $\mathrm{NH}_{2}$ was shown to be significantly more active than haemin, especially at higher $\mathrm{H}_{2} \mathrm{O}_{2}$ concentrations; therefore, indicating that the MOF provides some protective effect against the degradation of haem. It was also shown that the optimum temperature was $10{ }^{\circ} \mathrm{C}$ higher for haemin@MIL-101(Al)- $\mathrm{NH}_{2}$ than for native haemin, indicating that the MOF increased the thermal stability of haemin. It was also shown that the material loses its catalytic activity with each cycle and this was attributed to haemin being washed off the catalyst after being recovered.

The ability of the material to sense both $\mathrm{H}_{2} \mathrm{O}_{2}$ and glucose was probed. It was found that it could be used to detect $\mathrm{H}_{2} \mathrm{O}_{2}$ at concentrations starting at $2 \mu \mathrm{M}$ and showed a linear response for $\mathrm{H}_{2} \mathrm{O}_{2}$ concentration against absorbance between 5 and $200 \mu \mathrm{M}$. Sensing of glucose was investigated according to Scheme 9 by coupling the reaction of haemin@MIL-101(Al)- $\mathrm{NH}_{2}$ and $\mathrm{H}_{2} \mathrm{O}_{2}$ with the enzyme glucose oxidase (GOx). It was found that glucose could be sensed between 10 and $300 \mu \mathrm{M}$ and it was found that the sensing was substrate specific as no response was recorded when tested in the presence of fructose, lactose and maltose.

In a second report of a Fe(III)PPIX containing MOF by Luo et al. [123], a similar strategy to that reported by Larsen et al. [110] was employed. Haemin (Cl-Fe(III)PPIX) was encapsulated in Cu-HKUST-1 for the application of 
a

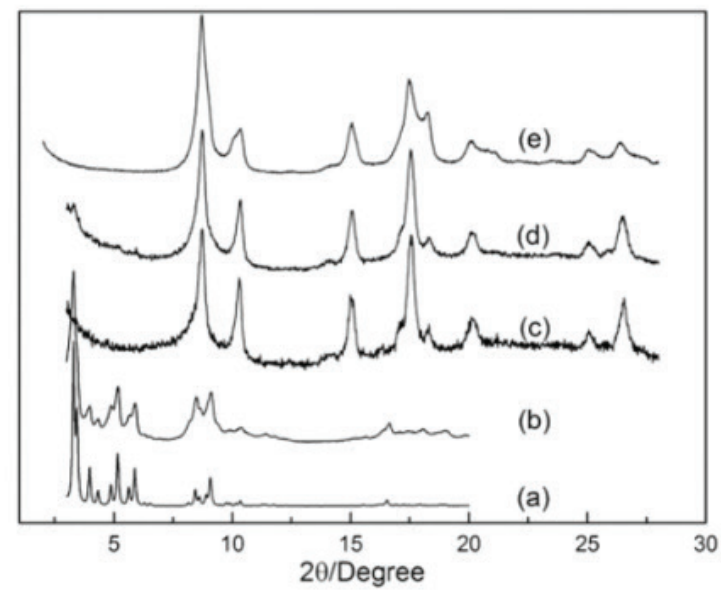

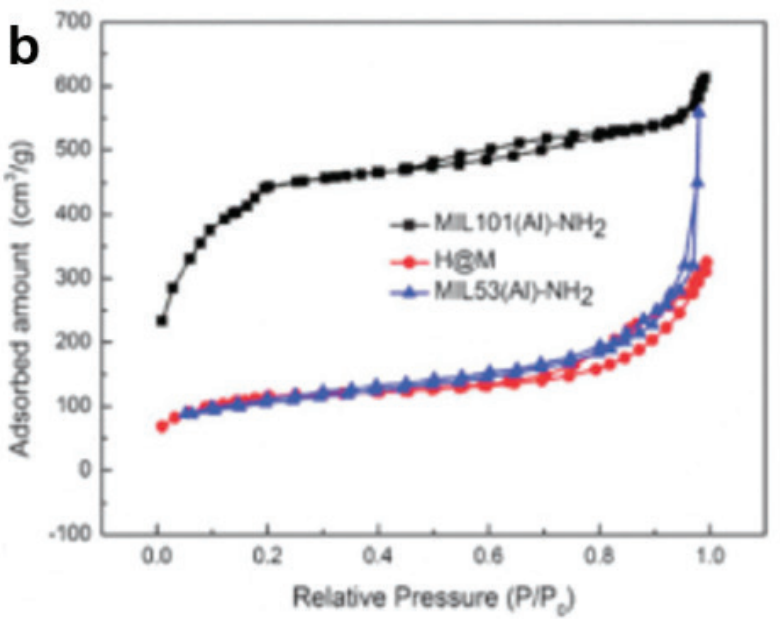

Figure 14: (a) PXRD patterns of simulated (a) MIL-101(Cr), (b) MIL-101(Al)-NH ${ }_{2}$, (c) synthesised haemin@MOF, (d) MIL-101(Al)-NH ${ }_{2}$ soaked in

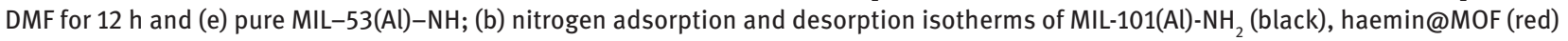
and MIL-53(Al)- $\mathrm{NH}_{2}$ (blue) [118]. Reprinted with permission from Ref. [118]. Copyright (C 2013, Royal Society of Chemistry.
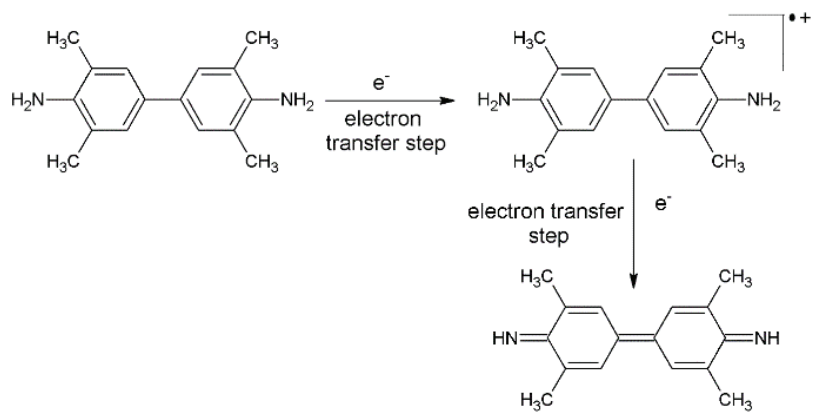

Figure 15: Mechanism of oxidation of TMB [122].

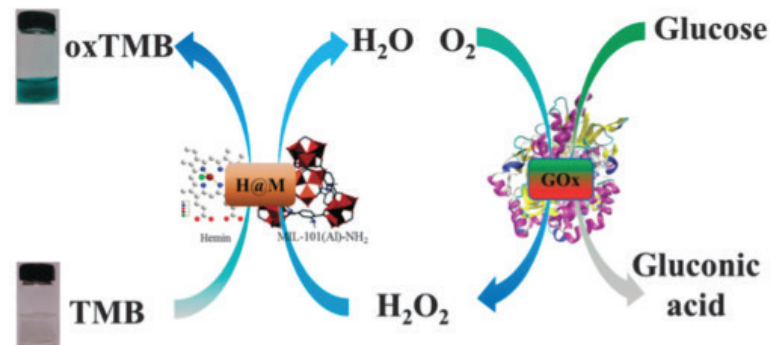

Scheme 9: Schematic illustration of colorimetric determination of glucose using glucose oxidase (GOx) and haemin@MIL-101(Al)- $\mathrm{NH}_{2}$ hybrid material -catalyszed reactions [118]. Reprinted with permission from Ref. [118]. Copyright (c) 2013, Royal Society of Chemistry.

sensing glucose and peroxide using chemiluminescence (Scheme 10) [123]. The octahedral pores of the HKUST-1 framework have previously been shown to be suitable for tetraphenylporphyrin oxidation [110,112], however, this was the first reported study of HKUST-1 being used to encapsulate native haem. PXRD was used to confirm that Cu-HKUST-1 had been formed, but contrary to previous reports of encapsulated $\mathrm{Fe}(\mathrm{III})$ tetraphenylporphyrins in HKUST-1 frameworks, no colour change was observed. This could indicate that only a minimal amount of haem was in fact encapsulated. This was further reinforced by a very small reported change in BET surface area of haemin@HKUST-1 compared to Cu-HKUST-1 (1160.9 m² $\mathrm{g}^{-1}$ vs. $1228.8 \mathrm{~m}^{2} \mathrm{~g}^{-1}$.

The synthesised haemin@MOF was investigated for its use as a glucose and $\mathrm{H}_{2} \mathrm{O}_{2}$ sensor using chemiluminescence produced by the oxidation of luminol by $\mathrm{H}_{2} \mathrm{O}_{2}$ which can be catalysed by a redox active metal. This is a well-known reaction and the chemiluminescence of luminol in the presence of $\mathrm{H}_{2} \mathrm{O}_{2}$ and haemin has been previously reported in the literature (Figure 16) [124,125]. To this end, it was shown that in the presence of haemin@ HKUST, $\mathrm{H}_{2} \mathrm{O}_{2}$ and luminol, a blue chemiluminescent glow was observed (Figure 17a). A plot of the chemiluminescent intensity revealed that no reaction was observed without the catalyst or in the presence of CuHKUST-1. A moderate reaction was observed in the presence of haemin@HKUST and the largest reaction was observed in the presence of free haemin (Figure 17b). It was also shown that the material retained its catalytic activity through eight catalytic cycles. The lack of chemiluminescence observed in the presence of Cu-HKUST-1 alone is contrary to the findings reported in a previous study which demonstrated that $\mathrm{Cu}$-HKUST-1 can successfully catalyse the reaction between $\mathrm{H}_{2} \mathrm{O}_{2}$ and luminol [126]. This would be expected 


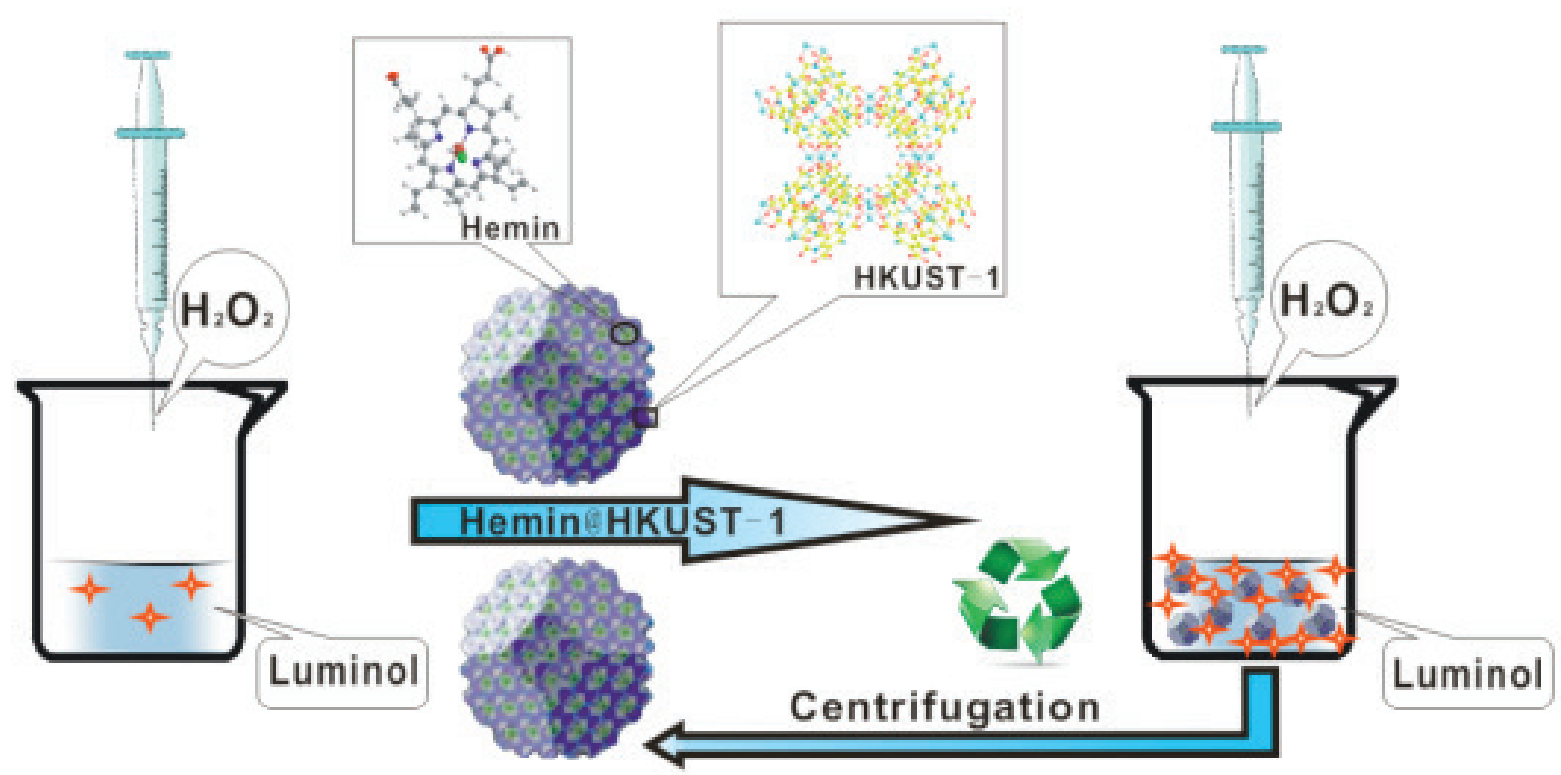

Scheme 10: Schematic of process used by Luo et al. for use of haemin@HKUST as a $\mathrm{H}_{2} \mathrm{O}_{2}$ sensor using chemiluminescence [123]. Reprinted with permission from Ref. [123]. Copyright @ 2015, American Chemical Society.

owing to the redox-active nature of $\mathrm{Cu}(\mathrm{II})$ ions present in the HKUST-1 framework.

The sensing activity of haemin@HKUST was studied by also investigating its ability to detect $\mathrm{H}_{2} \mathrm{O}_{2}$ and glucose in a similar manner to haemin@MIL-101(Al)- $\mathrm{NH}_{2}$. It was found that the material had a detection limit of $2 \mathrm{\mu M} \mathrm{H}_{2} \mathrm{O}_{2}$ and a plot of $\log \left(I_{C L}\right)$ vs. $\log \left[\mathrm{H}_{2} \mathrm{O}_{2}\right]$ showed a linear response between 5 and $1000 \mu \mathrm{M} \mathrm{H}_{2} \mathrm{O}_{2}$. Similarly, the detection limit for glucose was found to be $7.5 \mu \mathrm{M}$ and had a linear range from $7.5-750 \mu \mathrm{M}$. The authors concluded that the material showed promise as a hydrogen peroxide and glucose sensor.

A study was reported by Cheng et al. where Fe(III) PPIX was encapsulated in zeolitic imidazolate framework (ZIF-8) nanostructure for the design of integrated nanozymes (INAzymes) by co-encapsulating Fe(III)PPIX and glucose oxidase (GOx) in the same framework [127]. This material was investigated for its use as a colorimetric glucose sensor. Both the Fe(III)PPIX and Fe(III)PPIX/GOx containing materials were synthesised in an aqueous solution at room temperature by adding both the guests to be encapsulated as well as the components of the framework, yielding light green crystals with a rhombic dodecahedral shape with average sizes of ca. 210, 100, and $190 \mathrm{~nm}$ for ZIF-8, Fe(III)PPIX@ZIF-8 and Fe(III) PPIX/GOx@ZIF-8 (INAzyme), respectively (Scheme 11). The shape of the crystals became less regular with the inclusion of Fe(III)PPIX and Fe(III)PPIX/GOx. Element mapping with transmission electron microscopy (TEM)<smiles></smiles><smiles>Nc1cccc(C(=O)[O-])c1C(=O)[O-]</smiles>

Figure 16: Mechanism of chemiluminescence observed from haemin-catalysed oxidation of luminol by $\mathrm{H}_{2} \mathrm{O}_{2}$.

verified successful encapsulation of $\mathrm{Fe}(\mathrm{III}) \mathrm{PPIX}$ which showed a uniform distribution of $\mathrm{Fe}$ throughout the crystals. Successful encapsulation of GOx was confirmed by conjugating GOx with fluorescein isothiocyanate (FITC), and producing GOx-FITC/Fe(III)PPIX@ZIF-8. This demonstrated uniform fluorescence when the crystals were excited at $436 \mathrm{~nm}$.

The peroxidase mimicking ability of the synthesised haemin@ZIF-8 was evaluated by investigating the catalytic oxidation of ABTS by $\mathrm{H}_{2} \mathrm{O}_{2}$ (Scheme 6). It was found that haemin@ZIF-8 was peroxidatically active and showed an increase in activity relative to native haemin, demonstrating $90 \%$ retention of activity through 

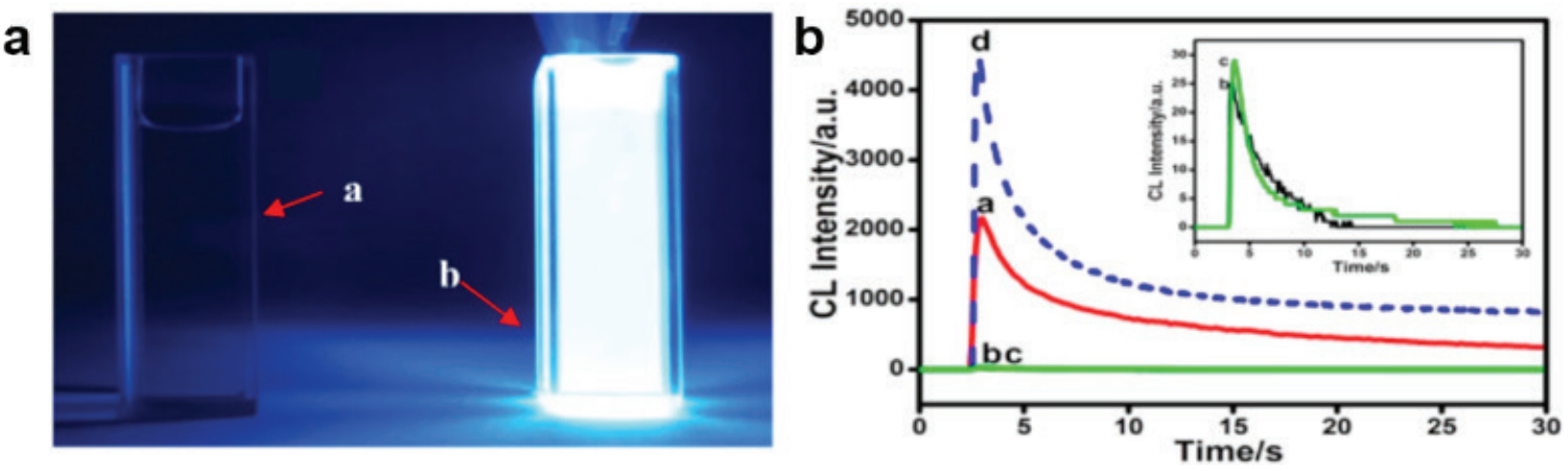

Figure 17: (a) Luminol in solution containing $\mathrm{H}_{2} \mathrm{O}_{2}$ without and with haemin@HKUST (left and right, respectively); (b) Chemiluminescence intensity observed in the presence of haemin@HKUST (red), with no catalyst (black), Cu-HKUST-1 (green) and free haemin (blue) [123]. Reprinted with permission from Ref. [123]. Copyright @ 2015, American Chemical Society.

multiple cycles. The catalytic activity of GOx/hemin@ ZIF-8 in cascade reactions was also investigated (Figure 18). The encapsulated GOx first catalysed the oxidation of glucose to gluconic acid with $\mathrm{O}_{2}$ to produce in situ $\mathrm{H}_{2} \mathrm{O}_{2}$ which subsequently oxidised ABTS, catalysed by the encapsulated haemin. The INAzyme material was found to be more active than a solution containing GOx and HRP and more active than the two components encapsulated separately (haemin@ZIF-8 and GOx@ZIF-8). Furthermore, the material demonstrated good recyclability through four cycles with approximately $80 \%$ of activity retained.

Due to the success seen in the initial experiments with GOx/haemin@ZIF-8, the material was evaluated for in vivo colorimetric detection of cerebral glucose in living mouse brains. It was found that it could be used to detect glucose in the range 0 to $250 \mu \mathrm{M}$ which covers the range of physiological levels of glucose and it was found that this material could accurately determine the concentration of glucose in living mouse brains, before and after global cerebral ischaemia. Furthermore, it was found that compounds such as ascorbic acid, lactate and dopamine which are also present in significant levels in the mouse brain did not interfere with the accurate detection of glucose at their physiological levels. Finally, the authors investigated the possibility of combining an INAzymemodified microfluidic chip with microdialysis technology for the continuous online monitoring of cerebral glucose and the successful monitoring of dynamic changes of cerebral glucose in living brains following ischaemia/ reperfusion was demonstrated.

The most recent study of Fe(III)PPIX being encapsulated in a MOF was reported by Dare et al. in 2018 [128]. In this study two redox inactive Zn MOFs, namely $\left[\mathrm{H}_{2} \mathrm{~N}\left(\mathrm{CH}_{3}\right)_{2}\right]\left[\mathrm{Zn}_{3}(\mathrm{TATB})_{2}(\mathrm{HCOO})\right] \cdot \mathrm{HN}\left(\mathrm{CH}_{3}\right)_{2} \cdot \mathrm{DMF} \cdot 6 \mathrm{H}_{2} \mathrm{O}$ (1) and Zn-HKUST-1 (2) were investigated for Fe(III)PPIX a

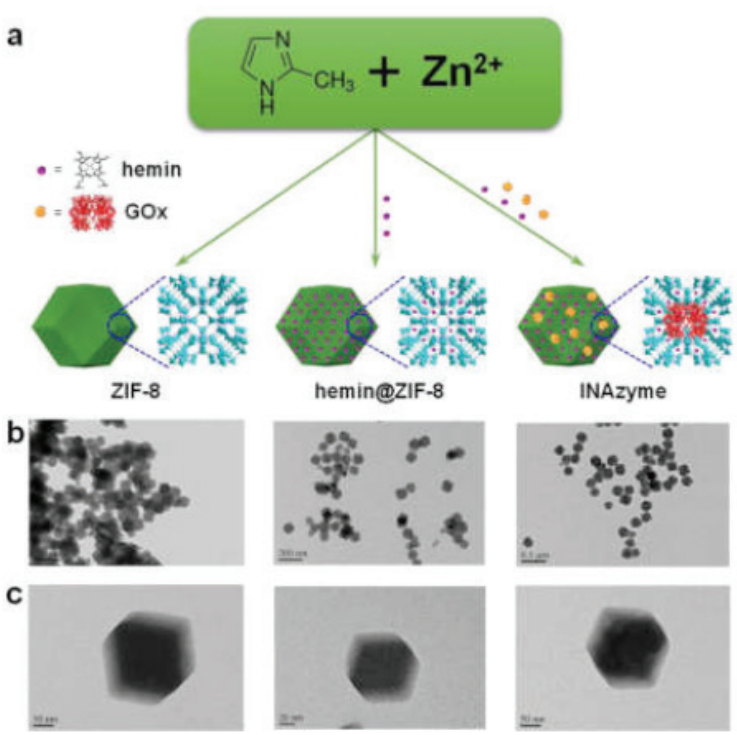

Scheme 11: (a) Schematic synthesis of nanoscaled ZIF-8, haemin@ ZIF-8 and GOx/haemin-ZIF-8 (INAzyme) from 2-methylimidazole and zinc acetate in a one-step protocol and models of the obtained materials (not drawn to scale); (b and c) TEM images of ZIF-8, haemin@ZIF-8 and G0x/haemin-ZIF-8 (INAzyme) from left to right at (b) low magnification and (c) high magnification) [127]. Reprinted with permission from Ref. [127]. Copyright (c) 2016, American Chemical Society.

encapsulation. The ability of substrates to diffuse in and out of the framework was investigated using methyl orange as a model substrate, and it was found that framework $\mathbf{1}$ had a large adsorption quotient, while $\mathbf{2}$ had a much lower adsorption quotient and displayed instability in the presence of water. Fe(III)PPIX was encapsulated in $\mathbf{1}$ using the 'ship-in-a-bottle' method described by Larsen et al. [110]. Encapsulation of Fe(III)PPIX did not significantly alter the structure of the framework, as seen by PXRD. 

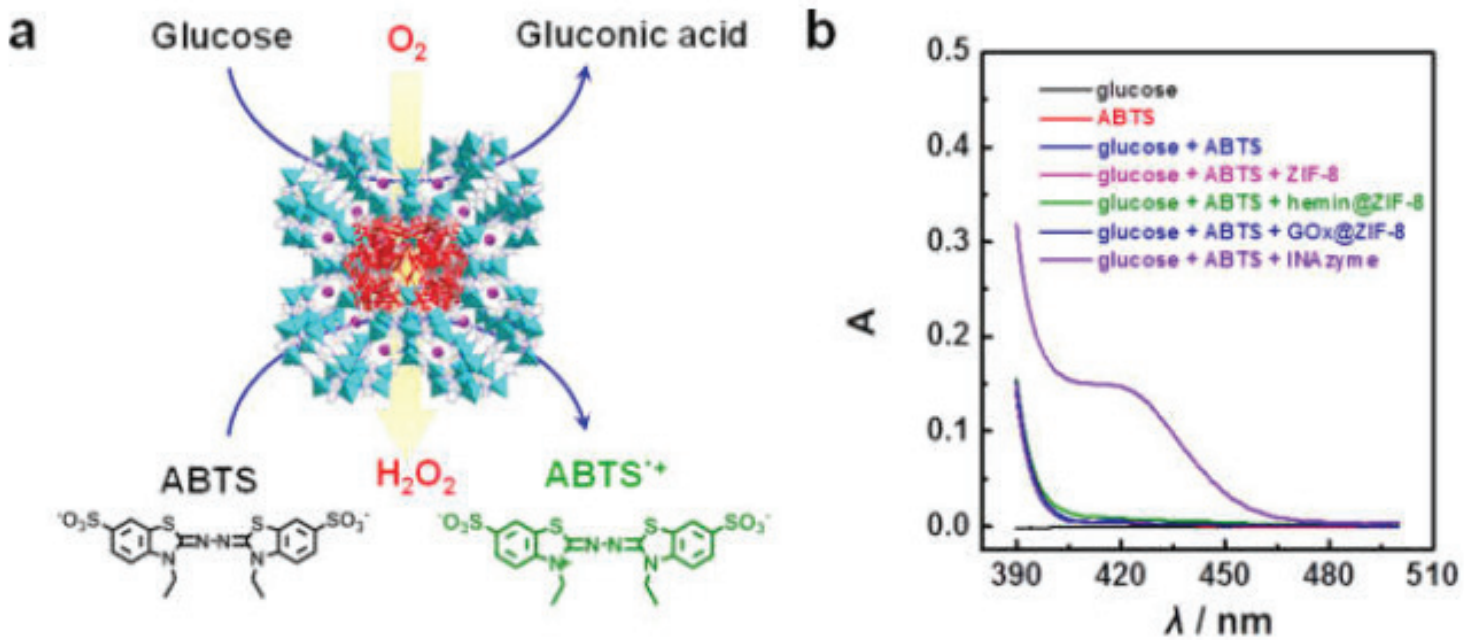

Figure 18: (a) Schematic illustration of GOx/haemin@ZIF-8 (INAzyme) cascade oxidation of glucose and ABTS to produce ABTS ${ }^{\bullet+}$; (b) Activity of GOx/haemin@ZIF-8 (INAzyme) and other components of the crystal system in $0.10 \mathrm{M}$ Tris-HCl buffer (pH 7.0), respectively [127]. Reprinted with permission from Ref. [127]. Copyright (C) 2016, American Chemical Society.

Successful encapsulation was further confirmed by SEMEDS, solid- and solution-state UV-visible spectroscopies, ICP-OES as well as a decrease in the Langmuir surface area as calculated from $\mathrm{N}_{2}$ adsorption isotherms. Importantly, solid-state UV-visible spectroscopy indicated that Fe(III)PPIX was encapsulated in a monomeric form and that FePPIX@1 retained its ability to adsorb the model substrate, methyl orange. Both factors indicated that it would be suitable as a heterogeneous catalyst.

Contrary to the previously reported examples of Fe(III)PPIX encapsulated MOFs, crystals suitable for single crystal XRD analysis were obtained in this study. While the full structure of Fe(III)PPIX in the framework could not be resolved, the $\mathrm{Fe}$ atom and pyrrole $\mathrm{N}$ atoms were located, enabling rigid-body modelling of the porphine core. It was found that Fe(III)PPIX was located in the 4 , helical channels of $\mathbf{1}$, rather than $\pi$ stacked with the triazine ligands (Figure 19). The inability to fully refine the Fe(III)PPIX molecule was attributed to the asymmetric nature of Fe(III)PPIX contributing to extensive disorder of $\mathrm{Fe}(\mathrm{III})$ PPIX in the channels of the MOF.

The catalytic activity of this MOF, as well as Fe(III) PPIX encapsulated in $\mathbf{2}$ was initially investigated using the oxidation of ABTS with $\mathrm{H}_{2} \mathrm{O}_{2}$ as an oxidant and compared to solid haemin as well as Fe(III)PPIX in solution (Figure 20). It was found that both the initial rate and yield of ABTS $^{\bullet}$ - formation for reactions catalysed by Fe(III)PPIX@1 and Fe(III)PPIX@2 were drastically increased compared to solid haemin and Fe(III)PPIX@1 was more active than Fe(III)PPIX@2. Interestingly, when comparing the catalytic activity Fe(III)PPIX@1 to a homogeneous Fe(III)

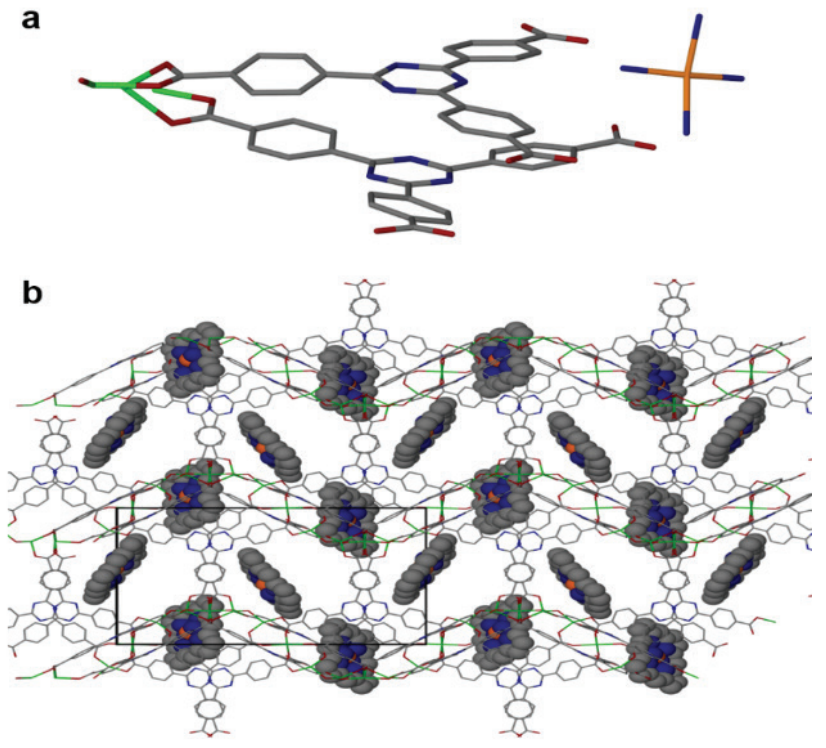

Figure 19: Crystal structure of Fe(III)PPIX@1. (a): Coordination environment of the asymmetric unit of Fe(III)PPIX@1 showing the located Fe and $\mathrm{N}$ atoms of Fe(III)PPIX in 1 and (b) packing of Fe(III) PPIX@1 viewed along the b-axis with a rigid-body model of the porphine core of Fe(III)PPIX in the channels of the framework (shown as space-fill; orange $=\mathrm{Fe}$, blue $=$ nitrogen) [128]. Reprinted with permission from Ref. [128]. Copyright $(\subset) 2018$, American Chemical Society.

PPIX solution, the reaction rate of the heterogeneous catalyst was only about six times slower; however, there was a two-fold increase in the yield of ABTS ${ }^{\bullet}$. This was attributed to the framework preventing aggregation and oxidative degradation of Fe(III)PPIX in aqueous solution. 


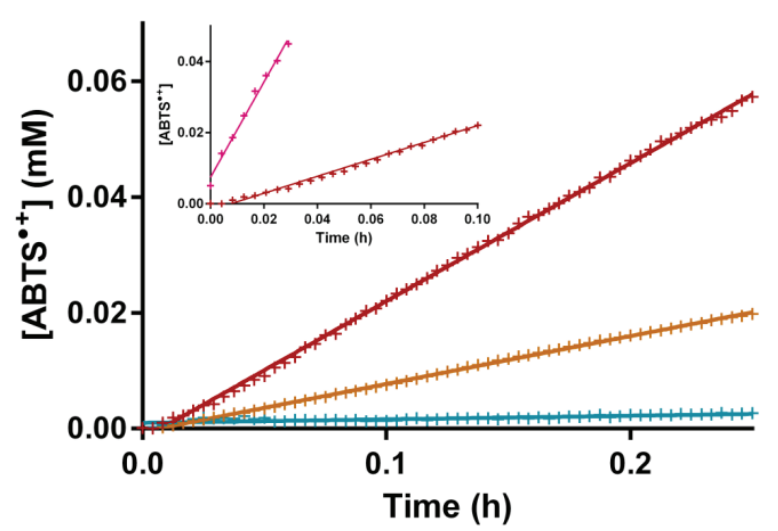

Figure 20: Initial rates of ABTS oxidation by $\mathrm{H}_{2} \mathrm{O}_{2}$ catalysed by Fe(III)PPIX@1 (red), Fe(III)PPIX@2 (orange) and solid Fe(III)PPIX-Cl (blue); Inset: Initial rate with Fe(III)PPIX@1 (red) and solution state Fe(III)PPIX (pink) [128]. Reprinted with permission from Ref. [128]. Copyright () 2018, American Chemical Society.

It was found that Fe(III)PPIX@1 retained its structural integrity through five catalytic cycles and could catalyse the oxidation of ABTS without loss of activity through these cycles.

The versatility of Fe(III)PPIX@1 as an oxidation catalyst was further probed by investigating the oxidation of a series of aromatic alcohols using UV-visible and NMR spectroscopies.Fe(III)PPIX@1 could catalyse the oxidation by ${ }^{\mathrm{BuOOH}}$ of hydroquinone, thymol, benzyl alcohol and phenyl ethanol to the corresponding aldehydes and ketones, however, the conversion percentage decreased and half-life of the reaction increased with increasing substrate size. This was attributed to the decreased ability of the substrate to diffuse into the channels of the framework with increasing size and suggests that this material may have size-selective properties.

There are four reports of Fe(III)PPIX@MOFs being used in composite materials for the construction of electrochemical sensors [129-132]. In a study by Song and co-workers, Fe(III)PPIX and $\mathrm{Cu}(\mathrm{II})\left(\mathrm{NO}_{3}\right)_{2}$ were sonicated together to create a $\mathrm{Fe}(\mathrm{III}) \mathrm{PPIX}-\mathrm{Cu}$ nanocomposite material (termed haemin-Cu MOF) which had a 3D ballflower-like structure [130]. This haemin-Cu MOF was then adhered to a chitosan-reduced graphene oxide (CSrGO) nanocomposite and the $\mathrm{H}_{2} \mathrm{O}_{2}$ sensing ability of this material investigated. It was found to have a linear range of $0.065-410 \mathrm{mM}$ and a detection limit of $0.019 \mathrm{mM}$.

The first reported example of a Fe(III)PPIX@MOF composite material was reported in 2015 by Yuan and co-workers [129]. In this study, the encapsulation approach to incorporate haemin into a nano-sized Fe-MIL-88 MOF which was subsequently coated with Au nanoparticles and conjugated to GOx for signal amplification and a thrombin binding aptamer in order to create an electrochemical aptasensor to detect thrombin (Scheme 12) [129].This sensor had a detection limit of $0.068 \mathrm{pM}$ and a wide linear range of $0.0001 \mathrm{nM}$ to $30 \mathrm{nM}$ for thrombin detection. These properties were attributed to the multifunctional nature of the material synthesised as well as the enzyme-assisted amplification of the signal created by binding of thrombin to the aptamer.

A recent study published by Yuan et al. once again makes use of the Fe(III)-MIL-88 framework to encapsulate Fe(III)PPIX, forming Fe(III)PPIX@Fe(III)-MIL-88- $\mathrm{NH}_{2}$. The surface of the crystal was subsequently decorated with $\mathrm{Pt}$ nanoparticles and $\mathrm{Cu}^{2+}$ ions creating a nanocomposite material capable of detecting the hypertensioncarrying adrenergic receptor gene (ADRB1) using the electrocatalytic oxidation of $\mathrm{H}_{2} \mathrm{O}_{2}$ by this nanocomposite material (Scheme 13) [131]. The sensor was created by immobilising the nanocomposite material on a GCE which was further functionalised with a capture DNA probe for the target ADRB1 gene. In the presence of the target gene, an electrochemical response could be measured resulting from the oxidation of $\mathrm{H}_{2} \mathrm{O}_{2}$. It was found that the sensor had a very wide linear range of $1 \mathrm{fM}$ to $10 \mathrm{nM}$ and had a $0.21 \mathrm{fM}$ detection limit.

A final example of Fe(III)PPIX@Fe-MIL-88 being incorporated into a nanocomposite material was reported by Chen et al. in 2017 who designed a sensor to detect the FGFR3 gene mutation [132]. This group coated the Fe(III) PPIX@Fe-MIL-88 material with Pt nanoparticles which was further coated with a thiol modified signal probe (SP) and bovine serum albumin. A GCE was modified with reduced graphene oxidetetraethylenepentamine (rGO-TEPA), gold nanoparticles and streptavidin for amplification of the signal and a biotin-modified capture probe was immobilised. The sensor could detect FGFR3 with a linear range $0.1 \mathrm{fM}$ to $1 \mathrm{nM}$ with a detection limit of 0.033 fM. For comparison, Fe(III)PPIX@Fe-MIL-88 was coated with Au nanoparticles as with the study by Yuan and co-workers. ${ }^{129}$ It was found that the Fe(III)PPIX@ Fe-MIL-88 material coated with Pt nanoparticles showed a much greater electrochemical response than its $\mathrm{Au}$ counterpart.

\section{Conclusion}

In this review, we have shown that a wide variety of solid supports have been successfully used for the encapsulation of both FePPIX and synthetic tetraphenylporphyrins to prepare heterogeneous oxidation catalysts. Most of 


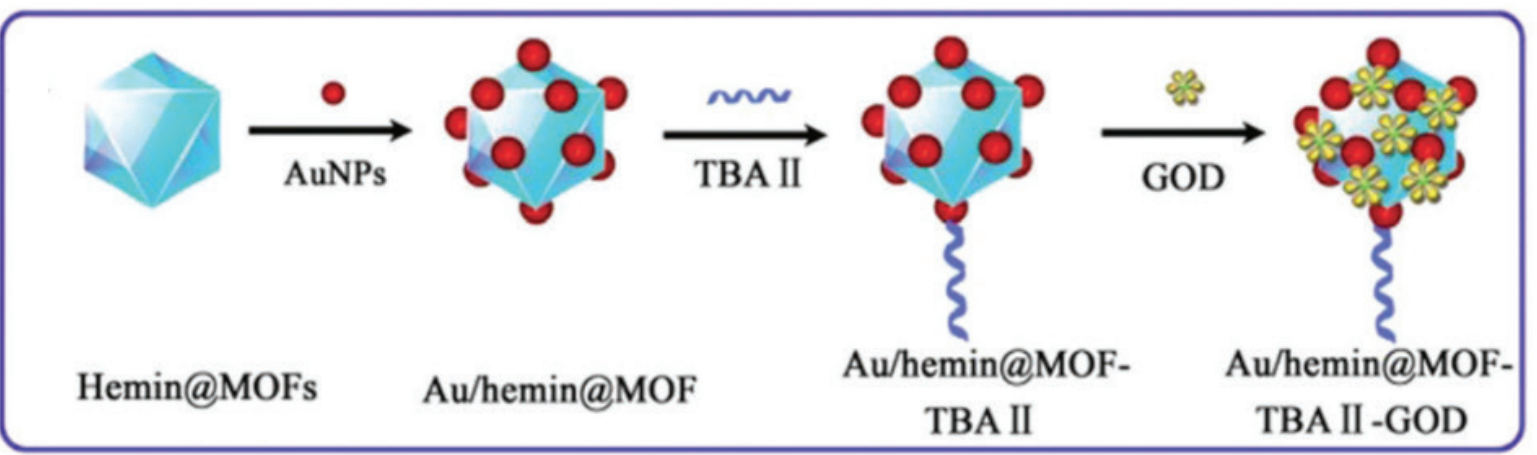

Scheme 12: The preparation of Au/hemin@MOF-TBA II-GOx bioconjugates. In the figure GOD represents GOx and TBA refers to the thrombin aptamer [129]. Reprinted with permission from Ref. [129]. Copyright @ 2015, Royal Society of Chemistry.
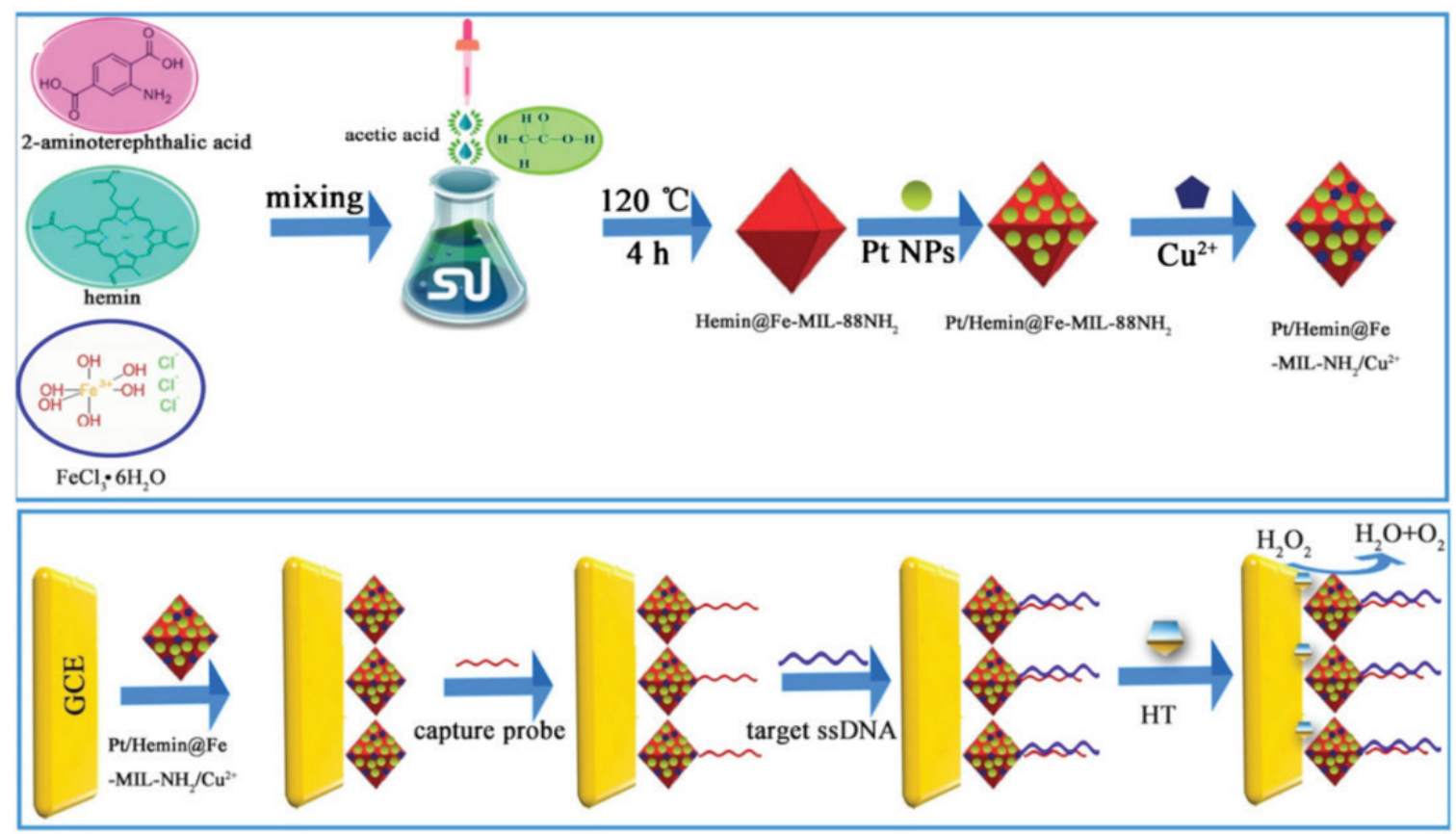

Scheme 13: The preparation process of Pt/Cu+2+/Fe(III)PPIX@Fe-MIL-88 $\mathrm{NH}_{2}$ (top) and schematic representation of construction of the electrochemical ADRB1 gene sensor [131]. Reprinted with permission from Ref. [131]. Copyright $\odot ~ 2017$, Springer.

the studies used the approach of synthesising the solid support around the porphyrin, coined the ship-in-thebottle' process. This process helps to prevent catalyst leaching, as the support is built around the catalyst itself and has been used with remarkable success in the field of metalloporphyrin@MOF catalysis. In most of the reported studies, encapsulation of the porphyrin resulted in a significant increase in the catalytic activity of the porphyrin when compared to its homogeneous counterpart. This indicates that by using this method of encapsulating porphyrins in solid supports to create a heterogeneous catalyst it is feasible to overcome some of the problems associated with porphyrin catalysis in solution. It is hypothesised that encapsulating the metalloporphyrin prevents porphyrin degradation, one of the most prevalent problems in homogeneous porphyrin catalysis. This is evidenced by the fact that most of the catalysts can be used through multiple cycles without significant loss of catalytic activity. Furthermore, it is likely that the increase in catalytic activity is also in part due to the solid support preventing porphyrin aggregation. These two processes have been identified as two of the main reasons for loss of catalytic activity of FePPIX when removed from a protein environment and the minimisation of these 
effects presents a significant advantage of the process of encapsulating FePPIX and other metalloporphyrins in solid supports for the application of heterogeneous oxidation catalysis.

It is also notable that there are many more examples of various synthetic porphyrins being encapsulated in a variety of supports. In all studies, the porphyrin was shown to play a crucial role in the activation of the oxidant used in the reaction and harnessing the power of FePPIX and other tetra-arylporphyrins has yielded a variety of active heterogeneous oxidation catalysts.

Direct comparisons of the activities of the reported materials, however, is difficult owing to the variety of reaction conditions used and the lack of catalyst loadings which are often omitted from these studies. It would be beneficial to have a standard set of conditions, or test reactions, which could be used as a baseline to assess catalyst activity across different systems. This would allow for better comparison of the synthesised catalysts and facilitate direct comparison of the catalytic activities of the different porphyrins as well as the utility of the various supports employed in this field. MOFs have been of great interest in this field, and this is reflected by the number of studies of metalloporphyrin@MOF systems in the literature. An additional shortfall that should be addressed is the lack of investigation of the effects of metalloporphyrin@MOF particle size and surface area. These properties are known to have an important impact in heterogeneous catalysis [133,134], and thus certainly warrant further investigation in future studies.

Conflict of interest: Authors state no conflict of interest.

\section{References}

[1] Dhakshinamoorthy A., Alvaro M., Garcia H., Metal-organic frameworks as heterogeneous catalysts for oxidation reactions, Catal. Sci. Technol., 2011, 1, 856-867.

[2] Ojeda M., Grau-Atienza A., Campo R., Romero A.A., Serrano E., Maria Marinas J., García Martínez J., Luque R., Hierarchical Zeolites and their Catalytic Performance in Selective Oxidative Processes, ChemSusChem, 2015, 8, 1328-1333.

[3] Pereira C., Simoes M., Tome J., Almeida Paz, F., PorphyrinBased Metal-Organic Frameworks as Heterogeneous Catalysts in Oxidation Reactions, Molecules, 2016, 21, 1348-1366.

[4] Chughtai A.H., Ahmad A.N., Younus H.A., Laypkov A., Verpoort F., Metal-organic frameworks: versatile heterogeneous catalysts for efficient catalytic organic transformations, Chem. Soc. Rev., 2015, 44, 6804-6849.

[5] Tundo P., Anastas P., Black D.S., Breen J., Collins T.J., Memoli S., Miyamoto J., Polyakoff M., Tumas W., Synthetic pathways and processes in green chemistry. Introductory overview, Pure Appl. Chem., 2000, 72, 1207-1228.

[6] Anastas P.T., Kirchhoff M.M., Williamson T.C., Catalysis as a foundational pillar of green chemistry, Appl. Catal. A Gen., 2001, 221, 3-13.

[7] Poulos T.L., Heme Enzyme Structure and Function, Chem. Rev., 2014, 114, 3919-3962.

[8] Groves J.T., In: Cytochrome P450, Structure, Mechanism, and Biochemistry, Ortiz de Montellano P.R., Springer US, Boston, MA, 2007.

[9] Fanelli A.R., Antonini E., Caputo A., In: Hemoglobin and Myoglobin, Vol. 19, Anfinsen C.B., Anson M.L., Edsall J.T., Richards F.M. (Eds.), Academic Press, Cambridge, Massachusetts, 1964.

[10] Gray H.B., Winkler J.R., Electron Transfer in Proteins, Annu. Rev. Biochem., 1996, 65, 537-561.

[11] Rodgers K.R., Heme-based sensors in biological systems, Curr. Opin. Chem. Biol., 1999, 3, 158-167.

[12] Meunier B., de Visser S.P., Shaik S., Mechanism of Oxidation Reactions Catalyzed by Cytochrome P450 Enzymes, Chem. Rev., 2004, 104, 3947-3980.

[13] Schmid A., Dordick J.S., Hauer B., Kiener A., Wubbolts M., Witholt B., Industrial biocatalysis today and tomorrow, Nature, 2001, 409, 258-268.

[14] Reedy C.J., Gibney B.R., Heme Protein Assemblies, Chem. Rev., 2004, 104, 617-649.

[15] RCSB Protein Data Bank https://www.rcsb.org/pdb/home/ home.do (accessed Jun 1, 2017).

[16] Roat-Malone R.M., Bioinorganic Chemistry; John Wiley \& Sons Inc. Hoboken, NJ, USA.

[17] Hersleth H.-P., Ryde U., Rydberg P., Görbitz C.H., Andersson K. K., Structures of the high-valent metal-ion haem-oxygen intermediates in peroxidases, oxygenases and catalases, J. Inorg. Biochem., 2006, 100, 460-476.

[18] Ortiz De Montellano P.R., Choe Y.S., DePillis G., Catalan C.E., Structure-Mechanism Relationships in Hemoproteins Oxygenations Catalyzed by Chloroperoxidase and Horseradish Peroxidase, J. Biol. Chem., 1987, 262, 1164-11646.

[19] Baker W.L., Removal of Ascorbic Acid Interference in Horseradish Peroxidase Estimations of Hydrogen Peroxide, Anal. Lett., 1998, 31, 1325-1335.

[20] Mao L., Luo S., Huang Q., Lu J., Horseradish peroxidase inactivation: heme destruction and influence of polyethylene glycol, Sci. Rep., 2013, 3, 3126.

[21] Karuzina I.I., Archakov A.I., The oxidative inactivation of cytochrome P450 in monooxygenase reactions, Free Radic. Biol. Med., 1994, 16, 73-97.

[22] Mansuy D., Battioni P., Bioinorganic catalysis, 2nd ed. Reedijk J., Bouwman E. (Eds.), Marcel Dekker Inc: New York, 1999.

[23] Poulos T.L., Kraut J., The Stereochemistry of Peroxidase Catalysis, J. Biol. Chem., 1980, 255, 8199-8205.

[24] Brausam A., Eigler S., Jux, N., van Eldik R., Mechanistic Investigations of the Reaction of an Iron(III) Octa-Anionic Porphyrin Complex with Hydrogen Peroxide and the Catalyzed Oxidation of Diammonium-2,2'-azinobis(3ethylbenzothiazoline-6-sulfonate), Inorg. Chem., 2009, 48, 7667-7678.

[25] Bruice T.C., Reactions of hydroperoxides with metallotetraphenylporphyrins in aqueous solutions, Acc. Chem. Res., 1991, 24, 243-249. 
[26] Lee W.A., Bruice T.C., Homolytic and Heterolytic OxygenOxygen Bond Scissions Accompanying Oxygen Transfer to Iron( 111) Porphyrins by Percarboxylic Acids and Hydroperoxides. A Mechanistic Criterion for Peroxidase and Cytochrome P-450, J. Am. Chem. Soc., 1985, 107, 514-516.

[27] Soper J.D., Kryatov S.V., Rybak-Akimova E.V., Nocera D.G., Proton-Directed Redox Control of O-O Bond Activation by Heme Hydroperoxidase Models, J. Am. Chem. Soc., 2007, 129, 5069-5075.

[28] Ortiz de Montellano P.R., Hydrocarbon hydroxylation by cytochrome P450 enzymes, Chem. Rev., 2010, 110, 932-948.

[29] Kaim W., Schwederski B., Bioinorganic Chemistry: Inorganic Elements in the Chemistry of Life, 2nd ed., John Wiley \& Sons Inc., Hoboken, NJ, 1991.

[30] Lindsay Smith J.R., Iamamoto Y., Vinhado F.S., Oxidation of alkanes by iodosylbenzene (PhIO) catalysed by supported $\mathrm{Mn}$ (III) porphyrins: Activity and mechanism, J. Mol. Catal. A Chem., 2006, 252, 23-30.

[31] Zipplies M.F., Lee W.A., Bruice T.C., Influence of Hydrogen Ion Activity and General Acid-Base Catalysis on the Rate of Decomposition of Hydrogen Peroxide by a Novel Nonaggregating Water-Soluble Iron(III) Tetraphenylporphyrin Derivative, J. Am. Chem. Soc., 1986, 108, 4433-4445.

[32] Guo C.-C., Song J.-X., Chen X.-B., Jiang G.-F., A new evidence of the high-valent oxo-metal radical cation intermediate and hydrogen radical abstract mechanism in hydrocarbon hydroxylation catalyzed by metalloporphyrins, J. Mol. Catal. A Chem., 2000, 157, 31-40.

[33] Meunie B., Metalloporphyrins as versatile catalysts for oxidation reactions and oxidative DNA cleavage, Chem. Rev., 1992, 92, 1411-1456.

[34] Sheldon R.A., Metalloporphyrins in Catalytic Oxidations, Marcel Dekker, New York, 1994.

[35] Hessenauer-Ilicheva N., Franke A., Meyer D., Woggon W.-D., van Eldik R., Low-Temperature Rapid-Scan Detection of Reactive Intermediates in Epoxidation Reactions Catalyzed by a New Enzyme Mimic of Cytochrome P450, J. Am. Chem. Soc., 2007, 129, 12473-12479.

[36] Nam W., Park S.-E., Lim I.K., Lim M.H., Hong J., Kim J., First Direct Evidence for Stereospecific Olefin Epoxidation and Alkane Hydroxylation by an Oxoiron(IV) Porphyrin Complex, J. Am. Chem. Soc., 2003, 125, 14674-14675.

[37] Adams P.A., The Peroxidasic Activity of the Haem Octapeptide Microperoxidase-8 (MP-8): The Kinetic Mechanism of the Catalytic Reduction of $\mathrm{H} 2 \mathrm{O} 2$ by MP-8 using 2,Z'- Azinobis(3-ethylbenzothiazoline-6-sulphonate) (ABTS) as Reducing Substrate, J. Chem. Soc. Perkin Trans., 1990, 2, 1407-1414.

[38] Meunier B., de Visser S.P., Shaik, S., Mechanism of Oxidation Reactions Catalyzed by Cytochrome P450 Enzymes, Chem. Rev., 2004, 104, 3947-3980.

[39] Nagababu E., Rifkind J.M., Heme Degradation by Reactive Oxygen Species, Antioxid. Redox Signal., 2004, 6, 967-978.

[40] Lan E.H., Dave B.C., Fukuto J.M., Dunn B., Zinkc J.I., Valentinec J.S., Synthesis of sol-gel encapsulated heme proteins with chemical sensing properties, J. Mater. Chem., 1999, 9, 45-53.

[41] Lloyd C.R., Eyring E.M., Protecting Heme Enzyme Peroxidase Activity from $\mathrm{H}_{2} \mathrm{O}_{2}$ Inactivation by Sol-Gel Encapsulation, Langmuir, 2000, 16, 9092-9094.
[42] Yan M., Ge J., Liu Z.A., Ouyang P., Encapsulation of Single Enzyme in Nanogel with Enhanced Biocatalytic Activity and Stability, J. Am. Chem. Soc., 2006, 128, 11008-11009.

[43] Liu Y., Zhang J., Hou W., Zhu J.-J., A Pd/SBA-15 composite: synthesis, characterization and protein biosensing, Nanotechnology, 2008, 19, 135707-135714.

[44] Dai Z., Liu S., Ju H., Chen H., Direct electron transfer and enzymatic activity of hemoglobin in a hexagonal mesoporous silica matrix, Biosens. Bioelectron., 2004, 19, 861-867.

[45] Lykourinou V., Chen Y., Wang X.-S., Meng L., Hoang T., Ming L.-J., Musselman R. L., Ma S., Immobilization of MP-11 into a Mesoporous Metal-Organic Framework, MP-11@mesoMOF: A New Platform for Enzymatic Catalysis, J. Am. Chem. Soc., 2011, 133, 10382-10385.

[46] Chen Y., Lykourinou V., Vetromile C., Hoang T., Ming L.-J., Larsen R.W., Ma S., How Can Proteins Enter the Interior of a MOF? Investigation of Cytochrome c Translocation into a MOF Consisting of Mesoporous Cages with Microporous Windows, J. Am. Chem. Soc., 2012, 134, 13188-13191.

[47] Lee C.-H., Lin T.-S., Mou C.-Y., Mesoporous materials for encapsulating enzymes, Nano Today, 2009, 4, 165-179.

[48] Díaz J.F., Balkus K.J., Enzyme immobilization in MCM-41 molecular sieve, J. Mol. Catal. B Enzym., 1996, 2, 115-126.

[49] Mehta J., Bhardwaj N., Bhardwaj S.K., Kim K.-H., Deep A., Recent advances in enzyme immobilization techniques: Metalorganic frameworks as novel substrates, Coord. Chem. Rev., 2016, 322, 30-40

[50] Chakraborty J., Nath, I., Verpoort F., Snapshots of encapsulated porphyrins and heme enzymes in metal-organic materials: A prevailing paradigm of heme mimicry, Coord. Chem. Rev., 2016, 326, 135-163.

[51] Lian X., Fang Y., Joseph E., Wang Q., Li J., Banerjee S., Lollar C., Wang X., Zhou H.-C., Enzyme-MOF (metal-organic framework) composites, Chem. Soc. Rev., 2017, 46, 3386-3401.

[52] Chen D., Feng H., Li J., Graphene Oxide: Preparation, Functionalization, and Electrochemical Applications, Chem. Rev., 2012, 112, 6027-6053.

[53] Chen W., Cai S., Ren Q.-Q., Wen W., Zhao Y.-D., Recent advances in electrochemical sensing for hydrogen peroxide: a review, Analyst, 2012, 137, 49-58.

[54] Su C., Loh K.P., Carbocatalysts: Graphene Oxide and Its Derivatives, Acc. Chem. Res., 2013, 46, 2275-2285.

[55] Kong J., Cheng W., Recent advances in the rational design of electrocatalysts towards the oxygen reduction reaction, Chinese J. Catal., 2017, 38, 951-969.

[56] Umeyama T., Imahori H., Photofunctional Hybrid Nanocarbon Materials, J. Phys. Chem. C, 2013, 117, 3195-3209.

[57] Zhang C., Chen P., Dong H., Zhen Y., Liu M., Hu W., Porphyrin Supramolecular 1D Structures via Surfactant-Assisted SelfAssembly, Adv. Mater., 2015, 27, 5379-5387.

[58] Barloy L., Battioni P., Mansuy D., Manganese porphyrins supported on montmorillonite as hydrocarbon monooxygenation catalysts: particular efficacy for linear alkane hydroxylation, J. Chem. Soc. Chem. Commun., 1990, 13651367.

[59] Nakagaki S., Halma M., Bail A., Arízaga G.G.C., Wypych F., First insight into catalytic activity of anionic iron porphyrins immobilized on exfoliated layered double hydroxides, J. Colloid Interface Sci., 2005, 281, 417-423. 
[60] Faria A.L., Mac Leod T.O.C., Barros V.P., Assis M.D., Hydrocarbon oxidation catalyzed by iron and manganese porphyrins anchored on aminofunctionalized supports, J. Braz. Chem. Soc., 2009, 20, 895-906.

[61] Nakagaki S., Benedito F.L., Wypych F., Anionic iron(III) porphyrin immobilized on silanized kaolinite as catalyst for oxidation reactions, J. Mol. Catal. A Chem., 2004, 217, 121-131.

[62] Nakagaki S., Machado G.S., Halma M., dos Santos Marangon A.A., de Freitas Castro K.A.D., Mattoso N., Wypych F., Immobilization of iron porphyrins in tubular kaolinite obtained by an intercalation/delamination procedure, J. Catal., 2006, 242, 110-117.

[63] Zhou W.-Y., Tian P., Sun F., He M.-Y., Chen Q., Highly efficient transformation of alcohol to carbonyl compounds under a hybrid bifunctional catalyst originated from metalloporphyrins and hydrotalcite, J. Catal., 2016, 335, 105-116.

[64] Itoh T., Yamada T., Kodera Y., Matsushima A., Hiroto M., Sakurai K., Nishimura H., Inada Y., Hemin (Fe3+)- and Heme (Fe2+)-Smectite Conjugates as a Model of Hemoprotein Based on Spectrophotometry, Bioconjug. Chem., 2001, 12, 3-6.

[65] Zhang L., Gu C., Xiong J., Yang M., Guo Y., Hemin-histaminemontmorillonite clay conjugate as a model biocatalyst to mimic natural peroxidase, Sci. China Chem., 2015, 58, 731-737.

[66] Beck J.S., Vartuli J.C., Roth W.J., Leonowicz M.E., Kresge C.T., Schmitt K.D., Chu C.T., Olson D.H., Sheppard E.W., McCullen S.B., Higgins J.B., Schlenkert J.L., A New Family of Mesoporous Molecular Sieves Prepared with Liquid Crystal Templates, J. Am. Chem. Soc., 1992, 114, 10834-10843.

[67] Kresge C.T., Leonowicz M.E., Roth W.J., Vartuli J.C., Beck J.S., Ordered mesoporous molecular sieves synthesized by a liquid-crystal template mechanism, Nature, 1992, 359, 710-712.

[68] Holland B.T., Walkup C., Stein A., Encapsulation, Stabilization, and Catalytic Properties of Flexible Metal Porphyrin Complexes in MCM-41 with Minimal Electronic Perturbation by the Environment, J. Phys. Chem. B, 1998, 102, 4301-4309.

[69] Nur H., Hamid H., Endud S., Hamdan H., Ramli Z., Ironporphyrin encapsulated in poly (methacrylic acid) and mesoporous Al-MCM-41 as catalysts in the oxidation of benzene to phenol, Mater. Chem. Phys., 2006, 96, 337-342.

[70] Rahiman A.K., Bharathi K.S., Sreedaran S., Rajesh K., Narayanan V., Cationic vanadyl porphyrin-encapsulated mesoporous Al/V-MCM-41 as heterogeneous catalysts for the oxidation of alkenes, Inorganica Chim. Acta, 2009, 362, 1810-1818.

[71] Rahiman A.K., Rajesh K., Bharathi K.S., Sreedaran S., Narayanan V., Catalytic oxidation of alkenes by manganese(III) porphyrin-encapsulated Al, V, Si-mesoporous molecular sieves, Inorganica Chim. Acta, 2009, 362, 1491-1500.

[72] Costa A.A., Ghesti G.F., de Macedo J.L., Braga V.S., Santos M.M., Dias J.A., Dias S.C.L., Immobilization of Fe, $\mathrm{Mn}$ and $\mathrm{Co}$ tetraphenylporphyrin complexes in MCM-41 and their catalytic activity in cyclohexene oxidation reaction by hydrogen peroxide, J. Mol. Catal. A Chem., 2008, 282, 149-157.

[73] Li Z., Xia C.-G., Zhang X.-M., Preparation and catalysis of DMY and MCM-41 encapsulated cationic Mn(III)-porphyrin complex, J. Mol. Catal. A Chem., 2002, 185, 47-56.

[74] Zhang J., Zhao G.-F., Popović Z., Lu Y., Liu Y., Pd-porphyrin functionalized ionic liquid-modified mesoporous SBA-15: An efficient and recyclable catalyst for solvent-free Heck reaction, Mater. Res. Bull., 2010, 45, 1648-1653.

[75] Zanatta L.D., Barbosa I.A., Zanardi F.B., de Sousa Filho P.C., Bolzon L.B., Ramos A.P., Serra O.A., lamamoto Y., Hydrocarbon oxidation by iron-porphyrin immobilized on SBA-15 as biomimetic catalyst: role of silica surface, RSC Adv., 2016, 6, 104886-104896.

[76] Zhao D., Sun J., Li Q., Stucky G.D., Morphological Control of Highly Ordered Mesoporous Silica SBA-15, Chem. Mater., 2000, 12, 275-279.

[77] Zhang J.-L., Liu Y.-L., Che C.-M., Chiral ruthenium porphyrin encapsulated in ordered mesoporous molecular sieves (MCM-41 and MCM-48) as catalysts for asymmetric alkene epoxidation and cyclopropanation, Chem. Commun., 2002, 2906-2907.

[78] Che C.-M., Huang J.-S., Lee F.-W., Li Y., Lai T.-S., Kwong H.-L., Teng P.-F., Lee W.-S., Lo W.-C., Peng S.-M., Zhou Z.-Y., Asymmetric Inter- and Intramolecular Cyclopropanation of Alkenes Catalyzed by Chiral Ruthenium Porphyrins. Synthesis and Crystal Structure of a Chiral Metalloporphyrin Carbene Complex, J. Am. Chem. Soc., 2001, 123, 4119-4129.

[79] Nazari K., Shokrollahzadeh S., Mahmoudi A., Mesbahi B., Seyed-Matin N., Moosavi-Movahedi A.A., Iron(III) protoporphyrin/MCM41 catalyst as a peroxidase enzyme model: Preparation and typical test reactions, J. Mol. Catal. A Chem., 2005, 239, 1-9.

[80] Weitkamp J., Zeolites and catalysis, Solid State Ion., 2000, 131, 175-188.

[81] Balkus K.J., Gabrielov A.G., Bell S.L., Bedioui F., Roue L., Devynck J., Zeolite Encapsulated Cobalt(II) and Copper(II) Perfluorophthalocyanines. Synthesis and Characterization, Inorg. Chem., 1994, 33, 67-72.

[82] Rosa I.L.V., Manso C.M.C.P., Serra O.A., Iamamoto Y., Biomimetical catalytic activity of iron(III) porphyrins encapsulated in the zeolite X, J. Mol. Catal. A Chem., 2000, 160, 199-208.

[83] Moghadam M., Tangestaninejad S., Mirkhani V., Mohammadpoor-Baltork I., Moosavifar M., Host (nanocavity of zeolite-Y or X)-guest (manganese (III) tetrakis[4-Nmethylpyridinum]porphyrin) nanocomposite materials as efficient catalysts for biomimetic alkene epoxidation with sodium periodate: Shape-selective epoxidation of linear alkenes, J. Mol. Catal. A Chem., 2009, 302, 68-75.

[84] Karimipour G., Rezaei M., Ashouri D., Zeolite Encapsulated Fe-poprhyrin for Catalytic Oxidation with lodobenzene Diacetate (Phl(OAc)2), J. Mex. Chem. Soc., 2013, 57, 276-282.

[85] Steed J.W., Supramolecular gel chemistry: developments over the last decade, Chem. Commun., 2011, 47, 1379-1383.

[86] Buerkle L.E., Rowan S.J., Supramolecular gels formed from multi-component low molecular weight species, Chem. Soc. Rev., 2012, 41, 6089.

[87] lamamoto Y., Ciuffi K.J., Sacco H.C., Prado C.M.C., de Moraes M., Nascimento O.R., Meso-aryl substituted metalloporphyrins supported on imidazole propyl gel (IPG). Catalytic activity in the oxidation of cyclohexane and characterization of iron porphyrin-IPG systems, J. Mol. Catal., 1994, 88, 167-176.

[88] Battioni P., Cardin E., Louloudi M., Schollhorn B., Spyroulias G.A., Mansuy D., Traylor T.G., Metalloporphyrinosilicas: a new class of hybrid organic-inorganic materials acting as selective 
biomimetic oxidation catalysts, Chem. Commun., 1996, 2037-2038.

[89] lamamoto Y., Ciuffi K.J., Sacco H.C., Iwamoto L.S., Nascimento O.R., Prado C.M., Characterization and catalytic activity of 2,6-dichlorophenyl substituted iron(III)porphyrin supported on silica gel and imidazole propyl gel, J. Mol. Catal. A Chem., 1997, 116, 405-420.

[90] De Paula R., Santos I.C.M.S., Simões M.M.Q., Neves M.G.P.M.S., Cavaleiro J.A.S., An immobilized imidazolyl manganese porphyrin for the oxidation of olefins, J. Mol. Catal. A Chem., 2015, 404-405, 156-166.

[91] Rahimi R., Ghoreishi S.Z., Dekamin M.G., Immobilized metalloporphyrins on 3-aminopropyl-functionalized silica support as heterogeneous catalysts for selective oxidation of primary and secondary alcohols, Monatsh. Chem., 2012, 143, 1031-1038.

[92] Gilmartin C., Lindsay Smith J.R., Alkene epoxidation by iodosylbenzene catalysed by iron(III) 5, 10, 15, 20-tetra(2,6dichlorophenyl)porphyrin coordinated to pyridine-modified silica, J. Chem. Soc. Perkin Trans., 2, 1995, 243-251.

[93] Benedito F.L., Nakagaki S., Saczk A.A., Peralta-Zamora P.G., Costa C.M.M., Study of metalloporphyrin covalently bound to silica as catalyst in the ortho-dianisidine oxidation, Appl. Catal. A Gen., 2003, 250, 1-11.

[94] Sharghi H., Beyzavi M.H., Doroodmand M.M., Reusable Porphyrinatoiron(III) Complex Supported on Activated Silica as an Efficient Heterogeneous Catalyst for a Facile, One-Pot, Selective Synthesis of 2-Arylbenzimidazole Derivatives in the Presence of Atmospheric Air as a "Green" Oxidant at Ambient Temperature, European J. Org. Chem., 2008, 2008, 41264138.

[95] Chen Z., Hua Z., Wang J., Guan Y., Zhao M., Li Y., Molecularly imprinted soluble nanogels as a peroxidase-like catalyst in the oxidation reaction of homovanillic acid under aqueous conditions, Appl. Catal. A Gen., 2007, 328, 252-258.

[96] Wang Q., Yang Z., Ma M., Chang C.K., Xu B., High Catalytic Activities of Artificial Peroxidases Based on Supramolecular Hydrogels That Contain Heme Models, Chem. Eur. J., 2008, 14, 5073-5078.

[97] Wang Q., Yang Z., Zhang X., Xiao X., Chang C.K., Xu B., A Supramolecular-Hydrogel-Encapsulated Hemin as an Artificial Enzyme to Mimic Peroxidase, Angew. Chem. Int. Ed. 2007, 46, 4285-4289.

[98] Chen Z., Xu L., Liang Y., Zhao M., pH-Sensitive Water-Soluble Nanospheric Imprinted Hydrogels Prepared as Horseradish Peroxidase Mimetic Enzymes, Adv. Mater., 2009, 22, 14881492.

[99] Wang Z., Chen G., Ding K., Self-Supported Catalysts, Chem. Rev., 2009, 109, 322-359.

[100] Perry IV J.J., Perman J.A., Zaworotko M.J., Design and synthesis of metal-organic frameworks using metal-organic polyhedra as supermolecular building blocks, Chem. Soc. Rev., 2009, 38, 1400-1417.

[101] Zhang Q., Zhang J., Yu Q.-Y., Pan M., Su C.-Y., Ring-Opening Isomerization Based on the 3-Connecting Node: Formation of a 0-D M2L3 Cage, 1-D Loop-and-Chain, and 2-D $(6,3)$ Network, Cryst. Growth Des., 2010, 10, 4076-4084.

[102] García-García P., Müller M., Corma A., MOF catalysis in relation to their homogeneous counterparts and conventional solid catalysts, Chem. Sci., 2014, 5, 2979-3007.
[103] Corma A., García H., Llabrés i Xamena F.X., Engineering Metal Organic Frameworks for Heterogeneous Catalysis, Chem. Rev., 2010, 110, 4606-4655.

[104] Furukawa H., Cordova K.E., O’Keeffe M., Yaghi O.M., The Chemistry and Applications of Metal-Organic Frameworks, Science, 341, 2013, 974.

[105] Gu Z.-Y., Park J., Raiff A., Wei Z., Zhou H.-C., Metal-Organic Frameworks as Biomimetic Catalysts, ChemCatChem, 2014, 6, 67-75.

[106] Zhang M., Gu Z.-Y., Bosch M., Perry Z., Zhou H.-C., Biomimicry in metal-organic materials, Coord. Chem. Rev., 2015, 293-294, 327-356.

[107] Gao W.-Y., Chrzanowski M., Ma S., Metal-metalloporphyrin frameworks: a resurging class of functional materials, Chem. Soc. Rev., 2014, 43, 5841-5866.

[108] Bélanger S., Hupp J.T., Porphyrin-Based Thin-Film Molecular Materials with Highly Adjustable Nanoscale Porosity and Permeability Characteristics, Angew. Chem. Int. Ed., 1999, 38 , 2222-2224.

[109] Alkordi M.H., Liu Y., Larsen R.W., Eubank J.F., Eddaoudi M., Zeolite-like Metal-Organic Frameworks as Platforms for Applications: On Metalloporphyrin-Based Catalysts, J. Am. Chem. Soc., 2008, 130, 12639-12641.

[110] Larsen R.W., Wojtas L., Perman J., Musselman R.L., Zaworotko M.J., Vetromile C.M., Mimicking Heme Enzymes in the Solid State: Metal-Organic Materials with Selectively Encapsulated Heme, J. Am. Chem. Soc., 2011, 133, 10356-10359.

[111] Larsen R.W., Miksovska J., Musselman R.L., Wojtas L., Ground- and Excited-State Properties of Zn(II) Tetrakis(4tetramethylpyridyl) Pophyrin Specifically Encapsulated within a Zn(II) HKUST Metal-Organic Framework, J. Phys. Chem. A, 2011, 115, 11519-11524.

[112] Zhang Z., Zhang L., Wojtas L., Eddaoudi M., Zaworotko M.J., Template-Directed Synthesis of Nets Based upon Octahemioctahedral Cages That Encapsulate Catalytically Active Metalloporphyrins, J. Am. Chem. Soc., 2012, 134, 928-933.

[113] Zhang Z., Zhang L., Wojtas L., Nugent P., Eddaoudi M., Zaworotko M.J., Templated Synthesis, Postsynthetic Metal Exchange, and Properties of a Porphyrin-Encapsulating MetalOrganic Material, J. Am. Chem. Soc., 2012, 134, 924-927.

[114] Zhang Z., Wojtas L., Zaworotko M.J., Three PorphyrinEncapsulating Metal-Organic Materials with Ordered Metalloporphyrin Moieties, Cryst. Growth Des., 2014, 14, 1526-1530.

[115] Li C., Qiu W., Long W., Deng F., Bai G., Zhang G., Zi X., He H., Synthesis of porphyrin@MOFs type catalysts through "one-pot” self-assembly, J. Mol. Catal. A Chem., 2014, 393, $166-170$.

[116] Ling P., Lei J., Zhang L., Ju H., Porphyrin-Encapsulated MetalOrganic Frameworks as Mimetic Catalysts for Electrochemical DNA Sensing via Allosteric Switch of Hairpin DNA, Anal. Chem., 2015, 87, 3957-3963.

[117] Mayer G., The Chemical Biology of Aptamers, Angew. Chem. Int. Ed., 2009, 48, 2672-2689.

[118] Qin F.-X., Jia S.-Y., Wang F.-F., Wu S.-H., Song J., Liu Y., Hemin@ metal-organic framework with peroxidase-like activity and its application to glucose detection, Catal. Sci. Technol., 2013, 3, 2761-2768. 
[119] Stavitski E., Goesten M., Juan-Alcañiz J., Martinez-Joaristi A., Serra-Crespo P., Petukhov A.V., Gascon J., Kapteijn F., Kinetic Control of Metal-Organic Framework Crystallization Investigated by Time-Resolved In Situ X-Ray Scattering, Angew. Chem. Int. Ed., 2011, 50, 9624-9628.

[120] Josephy P.D., Eling T., Mason Ronald P., The Horseradish Peroxidase-catalyzed Oxidation of 3,5,3',5'Tetramethylbenzidine, J. Biol. Chem., 1982, 257, 3669-3675.

[121] Marquez L.A., Dunford B.H., Mechanism of the Oxidation of 3,5,3',5'-Tetramethylbenzidine by Myeloperoxidase Determined by Transient- and Steady-State Kinetics, Biochemistry, 1997, 36, 9349-9355.

[122] Stefan L., Denat F., Monchaud D., Insights into how nucleotide supplements enhance the peroxidase-mimicking DNAzyme activity of the G-quadruplex/hemin system, Nucleic Acids Res., 2012, 40, 8759-8772.

[123] Luo F., Lin Y., Zheng L., Lin X., Chi Y., Encapsulation of Hemin in Metal-Organic Frameworks for Catalyzing the Chemiluminescence Reaction of the H2O2-Luminol System and Detecting Glucose in the Neutral Condition, ACS Appl. Mater. Interfaces, 2015, 7, 11322-11329.

[124] Motsenbocker M.A., Sensitivity limitations encountered in enhanced horseradish peroxidase catalysed chemiluminescence, J. Biolumin. Chemilumin., 1988, 2, 9-16.

[125] Easton P.M., Simmonds A.C., Rakishev A., Egorov A.M., Candeias L.P., Quantitative Model of the Enhancement of Peroxidase-Induced Luminol Luminescence, J. Am. Chem. Soc., 1996, 118, 6619-6624.

[126] Zhu Q., Chen Y., Wang W., Zhang H., Ren C., Chen H., Chen $\mathrm{X}$., A sensitive biosensor for dopamine determination based on the unique catalytic chemiluminescence of metal-organic framework HKUST-1, Sensors Actuators B Chem., 2015, 210, 500-507.

[127] Cheng H., Zhang L., He J., Guo W., Zhou Z., Zhang X., Nie S., Wei H., Integrated Nanozymes with Nanoscale Proximity for in Vivo Neurochemical Monitoring in Living Brains, Anal. Chem., 2016, 88, 5489-5497.
[128] Dare N.A., Brammer L., Bourne S.A., Egan T.J., Fe(III) protoporphyrin IX encapsulated in a zinc metal-organic framework shows dramatically enhanced peroxidatic activity, Inorg. Chem., 2018, 57, 1171-1183.

[129] Xie S., Ye J., Yuan Y., Chai Y., Yuan R., A multifunctional hemin@metal-organic framework and its application to construct an electrochemical aptasensor for thrombin detection, Nanoscale, 2015, 7, 18232-18238.

[130] Wang L., Yang H., He J., Zhang Y., Yu J., Song Y., Cu-Hemin Metal-Organic-Frameworks/Chitosan-Reduced Graphene Oxide Nanocomposites with Peroxidase-Like Bioactivity for Electrochemical Sensing, Electrochim. Acta, 2016, 213, 691-697.

[131] Yuan G., Wang L., Mao D., Wang F., Zhang J., Voltammetric hybridization assay for the $\beta 1$-adrenergic receptor gene (ADRB1), a marker for hypertension, by using a metal organic framework (Fe-MIL-88NH2) with immobilized copper(II) ions, Microchim. Acta, 2017, 184, 3121-3130.

[132] Chen J., Yu C., Zhao Y., Niu Y., Zhang L., Yu Y., Wu J., He J., A novel non-invasive detection method for the FGFR3 gene mutation in maternal plasma for a fetal achondroplasia diagnosis based on signal amplification by hemin-MOFs/ PtNPs, Biosens. Bioelectron., 2017, 91, 892-899.

[133] Leofantia G., Padovanb M., Tozzolac G., Venturellic B., Surface area and pore texture of catalysts, Catal. Today, 1998, 41, 207-219.

[134] Boudart M., Djega-Mariadassou G., Kinetics of Heterogeneous Catalytic Reactions, Princeton University Press, Princeton, NJ, 1984. 